\title{
Intramolecular Baylis-Hillman reaction: synthesis of heterocyclic molecules
}

\author{
Deevi Basavaiah*and Guddeti Chandrashekar Reddy \\ School of Chemistry, University of Hyderabad, Hyderabad, 500 046, India \\ E-mail: dbsc@uohyd.ernet.in, basavaiahdchem@uohyd.ac.in
}

Dedicated to Dr. J. S. Yadav on his $65^{\text {th }}$ birthday

DOI: :http://dx.doi.org/10.3998/ark.5550190.p009.322

\begin{abstract}
The Baylis-Hillman (BH) [also known as the Morita-Baylis-Hillman (MBH)] reaction is a versatile atom-economic $\mathrm{C}-\mathrm{C}$ bond forming reaction between the $\alpha$-position of activated alkenes and electrophiles under the influence of a catalyst and provides interesting classes of densely functionalized molecules. Its intramolecular version is yet another fascinating reaction by itself, producing various carbocylic and heterocyclic compounds of synthetic and medicinal relevance. Applications of the intramolecular Baylis-Hillman reaction in obtaining heterocyclic molecules of different ring sizes and also to the synthesis of various natural products/bioactive compounds containing heterocyclic frameworks are presented in this brief review.
\end{abstract}

Keywords: Baylis-Hillman reaction, Rauhut-Currier reaction, activated alkene, electrophile, heterocyclic molecules, natural products

\section{Table of Contents}

1. Introduction: the Baylis-Hillman (BH) Reaction

2. Intramolecular Baylis-Hillman (IBH) Reactions

2.1. IBH reactions: Activated alkene ( $\alpha, \beta$-unsaturated ester)-aldehyde system

2.2. IBH reactions: Activated alkenes ( $\alpha, \beta$-unsaturated sulfonates or $\alpha, \beta$-unsaturated sulfonamides)-aldehyde system

2.3. IBH reactions: Activated alkene ( $\alpha, \beta$-unsaturated amide)-aldehyde system

2.4. IBH reactions: Activated alkene ( $\alpha, \beta$-unsaturated sulfonamide)-ketone system

2.5. IBH reactions: Activated alkene ( $\alpha, \beta$-unsaturated amide)-ketone system

2.6. IBH reactions: Activated alkene (vinylquinoline)-imine system

2.7. Unusual Intramolecular Baylis-Hillman reactions 
2.8. Asymmetric intramolecular Baylis-Hillman (IBH) reactions

2.8.1. Asymmetric IBH reactions of enantiomerically enriched/pure substrates containing activated alkene and prochiral electrophile components, using achiral catalyst

2.8.2. Asymmetric IBH reactions of substrates containing activated alkene and prochiral electrophile components, using chiral catalyst

2.9. Applications to synthesis of biologically active molecules and natural products

3. Intramolecular BH reactions (activated alkene-activated alkene system) [also known as intramolecular Rauhut-Currier (IRC) reactions]

3.1. Asymmetric intramolecular Rauhut-Currier reactions

3.2. Applications of intramolecular Rauhut-Currier reactions

4. Future Challenges and Projections

5. Conclusions

6. Abbreviations

Acknowledgements

References

\section{Introduction}

Organic synthesis occupies a unique place among all the branches of science because of its extensive applications and direct impact on society. ${ }^{1-4}$ Now it is possible to synthesize any organic compound that is needed. Organic synthesis, in fact, mostly involves C-C bond forming reactions and functional group transformations. ${ }^{5-9}$ Therefore development of methodologies for construction of $\mathrm{C}-\mathrm{C}$ bonds that produce molecules containing several functional groups in proximity has become a highly challenging and attractive endeavor in organic chemistry. ${ }^{5-9}$ The Baylis-Hillman (BH) reaction ${ }^{10,11}$ [also known as the Morita ${ }^{12,13}$-Baylis-Hillman (MBH) reaction] is one such important $\mathrm{C}-\mathrm{C}$ bond forming reaction, providing densely functionalized molecules in an atom-economical process (Figure 1). This is a three component reaction and involves $\mathrm{C}$ - $\mathrm{C}$ bond formation between the $\alpha$-position of activated alkenes with electrophiles under the influence of a catalyst. One of the interesting and useful aspects of this reaction is that it usually provides molecules having a minimum of three functional groups in proximity, that is, $\alpha, \alpha$ - to each other. Over the past three decades this reaction has grown from obscurity (actually buried in the literature) to a high level of popularity and applicability. It is now a very wellknown organic reaction and is widely used as a powerful synthetic tool in organic chemistry. ${ }^{14-30}$ 


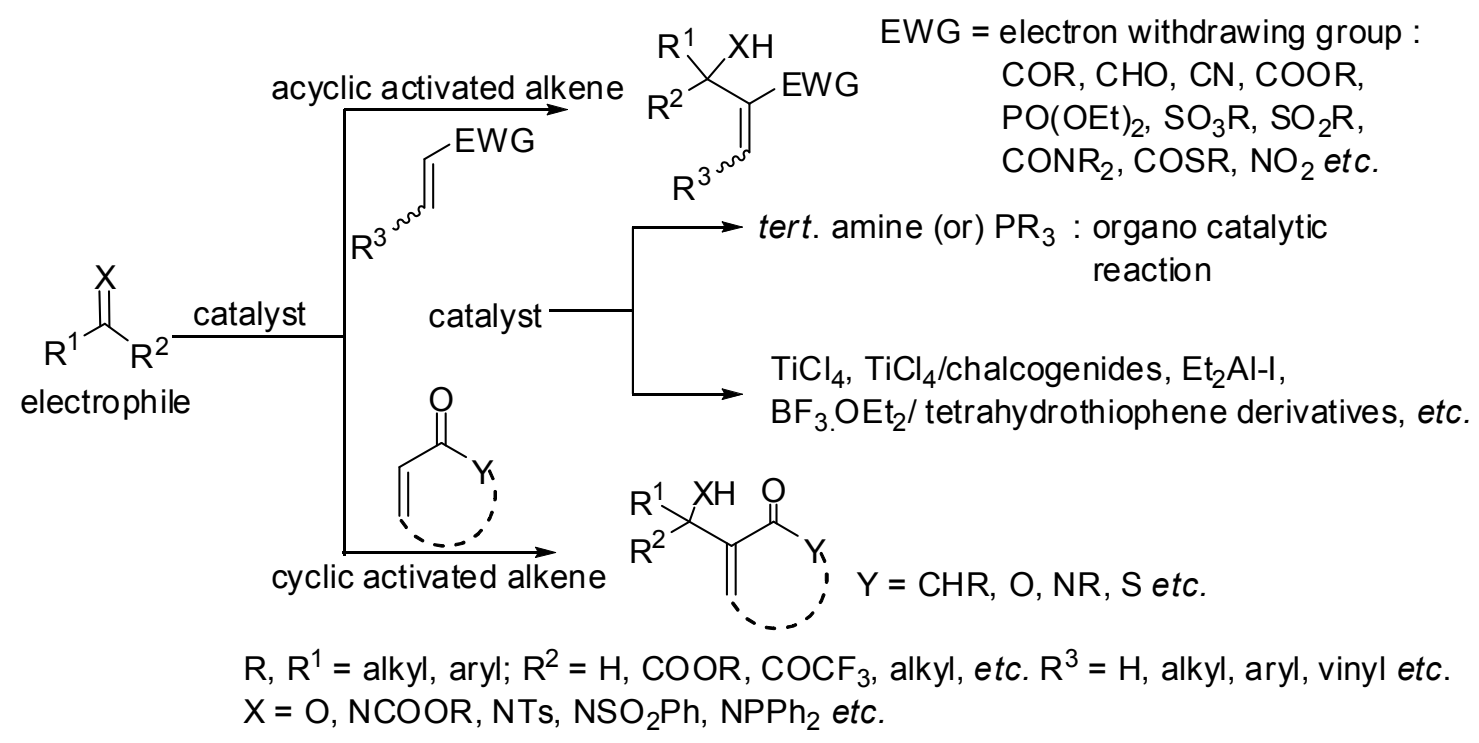

Figure 1. The Baylis-Hillman reaction at a glance.

In the most widely accepted mechanism of this fascinating carbon-carbon bond-forming reaction four steps are believed to be involved. A model case is presented in Scheme 1 by taking as an example the reaction between methyl acrylate and benzaldehyde catalyzed by DABCO. The first-step involves addition of the catalyst to the activated alkene (methyl acrylate) in a Michael fashion to generate in situ a zwitterionic enolate (A). The second step proceeds by addition of the zwitterionic enolate (A) to the electrophile (benzaldehyde) to give a zwitterionic aldol adduct (B) which in a third step undergoes a proton shift from the carbon $\alpha$ - to the ester group to oxygen ion to generate a zwitterion $(\mathbf{C})$. In the fourth step, the catalyst (DABCO) is released to produce the densely functionalized adduct, which is normally referred to as the Baylis-Hillman adduct (D). 




Scheme 1. Mechanism of the amine-catalyzed Baylis-Hillman reaction.

The exponential growth of this reaction may be attributed to the five important features: (1) It is an atom-economical $\mathrm{C}$-C bond forming reaction. (2) This is an organo-catalytic reaction because most of the catalysts are organic molecules (tertiary amines and phosphines). (3) It creates a chiral center in the product in the case of prochiral electrophile thus providing opportunities to develop its asymmetric version. (4) If the substrate contains both the activated alkene and electrophilc components in appropriate positions there is a possibility of performing intramolecular $\mathrm{BH}$ reaction producing various carbocycles and heterocycles. It, thus, creates opportunities for designing such substrates for intramolecular $\mathrm{BH}$ reaction and also offers opportunities to develop its asymmetric version. (5) It produces molecules containing a minimum of three proximal functional groups which are of tremendous potential in synthetic and mechanistic organic chemistry. In fact the wide popularity and applicability of this reaction can be easily understood by publications of a number of major ${ }^{14-22}$ and mini reviews ${ }^{23-30}$ and more than 3200 research articles during the past three decades.

\section{Intramolecular Baylis-Hillman (IBH) reactions}

As mentioned above, if a substrate is designed so as to have activated alkene and electrophile components in required orientation there is a possibility of performing intramolecular coupling 
reaction to produce carbocyclic/heterocyclic compounds of synthetic importance. Such an intramolecular version can be, in principle, performed using (1) various activated alkenes $(\alpha, \beta$ unsaturated esters / ketones / nitrile / thioesters / sulfonates / amides / sulfonamides / sulfones / sulfoxides etc.)- electrophiles (aldehydes / ketones / $\alpha$-keto-esters / aldimines / epoxides / halides etc.) systems (2) activated alkene-activated alkene (Rauhut-Currier reaction) ${ }^{31-34}$ system. Substrates for intramolecular BH reaction can in principle be designed so as to have the resulting cyclic compounds with an endocyclic double bond (Scheme 2: Paths A and C) or with exocyclic double bond (Scheme 2: Paths B and D).

The first intramolecular Baylis-Hillman reaction was reported as early as 1992 by Frater and co-workers. ${ }^{35}$ In fact, this is a landmark publication in the sense that ketones are used as electrophile components (Equation 1). They have also reported intramolecular BH reaction of the ene-ester $(\alpha, \beta$-unsaturated ester)-ketone substrate under the influence of chiral catalysts, (-)-CAMP and Li-quinidinate (Equations 2 and 3). ${ }^{35}$ Even though the yields and enantioselectivities are not that high, this strategy paved the way for intramolecular BH-reaction, its asymmetric version and also demonstrated the possible application of ketones as electrophiles in the BH-reaction. ${ }^{35}$

Subsequently various substrates and strategies were designed for intramolecular BH-reaction. This mini review presents the literature on the intramolecular Baylis-Hillman reaction and its asymmetric version with an emphasis on the synthesis of heterocycles and application to the synthesis of natural products / bioactive compounds containing heterocyclic frameworks.

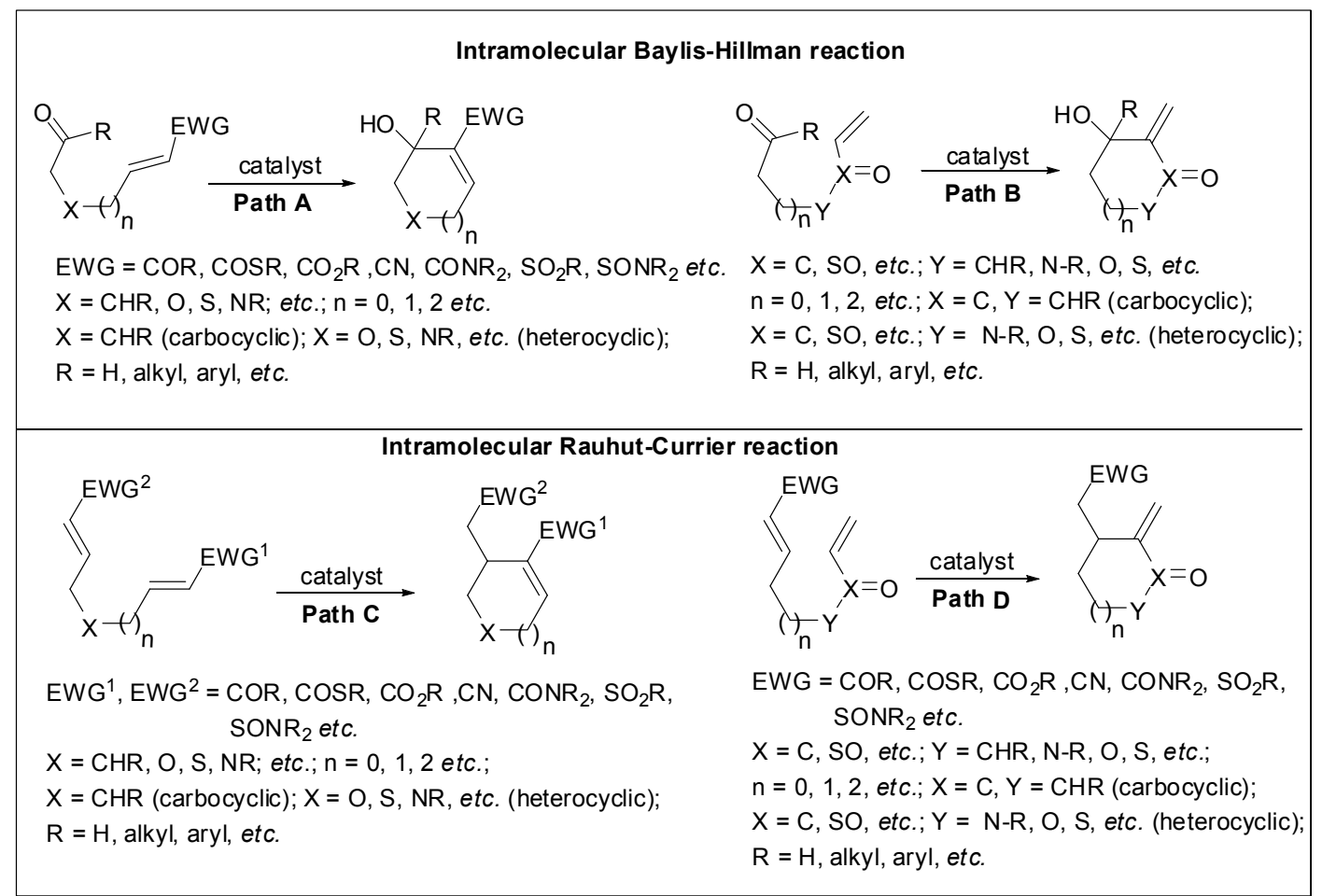

Scheme 2. Different modes of intramolecular Baylis-Hillman reaction. 


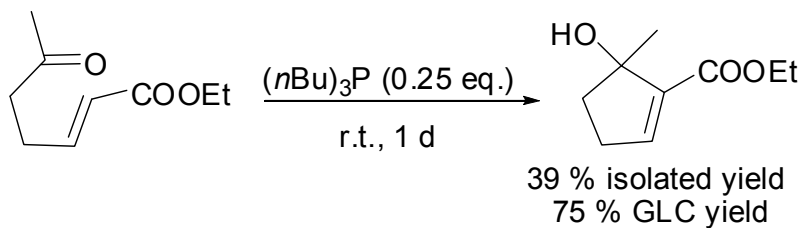

Equation 1. Intramolecular BH (IBH) reaction of $\alpha, \beta$-unsaturated ester-ketone.

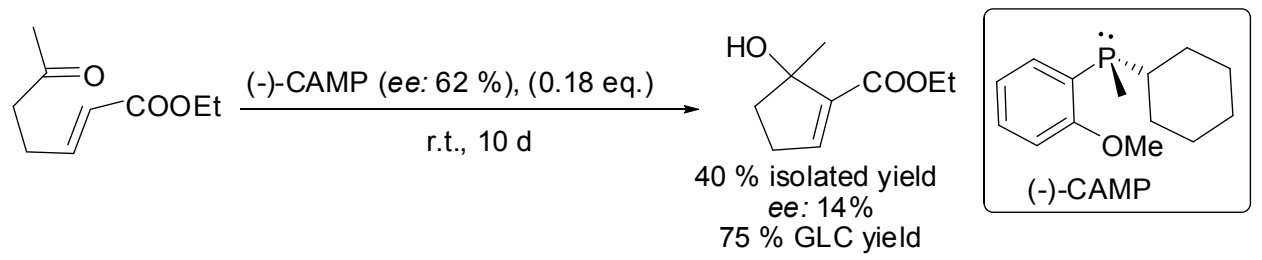

Equation 2. Asymmetric IBH reaction of $\alpha, \beta$-unsaturated ester-ketone using (-)-CAMP as catalyst.

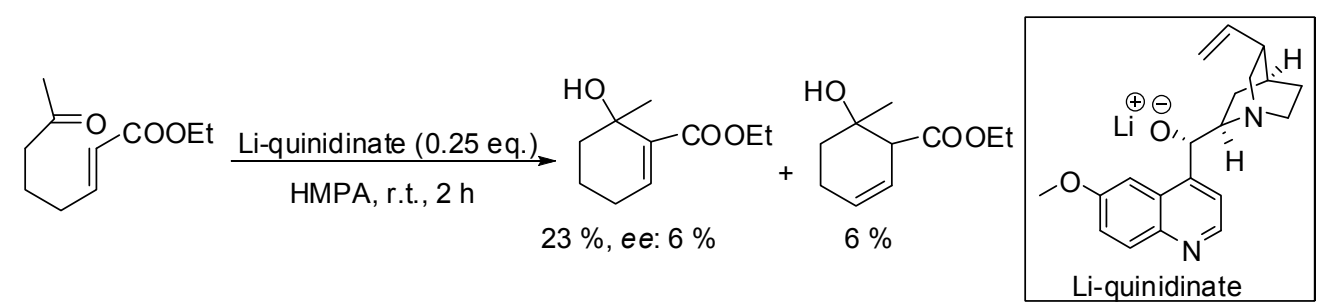

Equation 3. Li-quinidinate catalyzed asymmetric IBH reaction of $\alpha, \beta$-unsaturated ester-ketone.

\subsection{IBH reactions: activated alkene ( $\alpha, \beta$-unsaturated ester)-aldehyde system}

Drewes and co-workers reported an interesting intramolecular Baylis-Hillman reaction of acrylate-aldehyde 1 (obtained via the treatment of salicylaldehyde with acryloyl chloride) in presence of DABCO which provided the coumarin salt $\mathbf{2}$ as a major product and the rearranged $\mathrm{B}-\mathrm{H}$-alcohol 3 as a minor product (Scheme 3). ${ }^{36}$ It is believed that initially the Baylis-Hillman adduct was formed which was subsequently converted into coumarin-chloride salt on reaction with $\mathrm{CH}_{2} \mathrm{Cl}_{2}$ and DABCO (Scheme 3). ${ }^{36}$ 

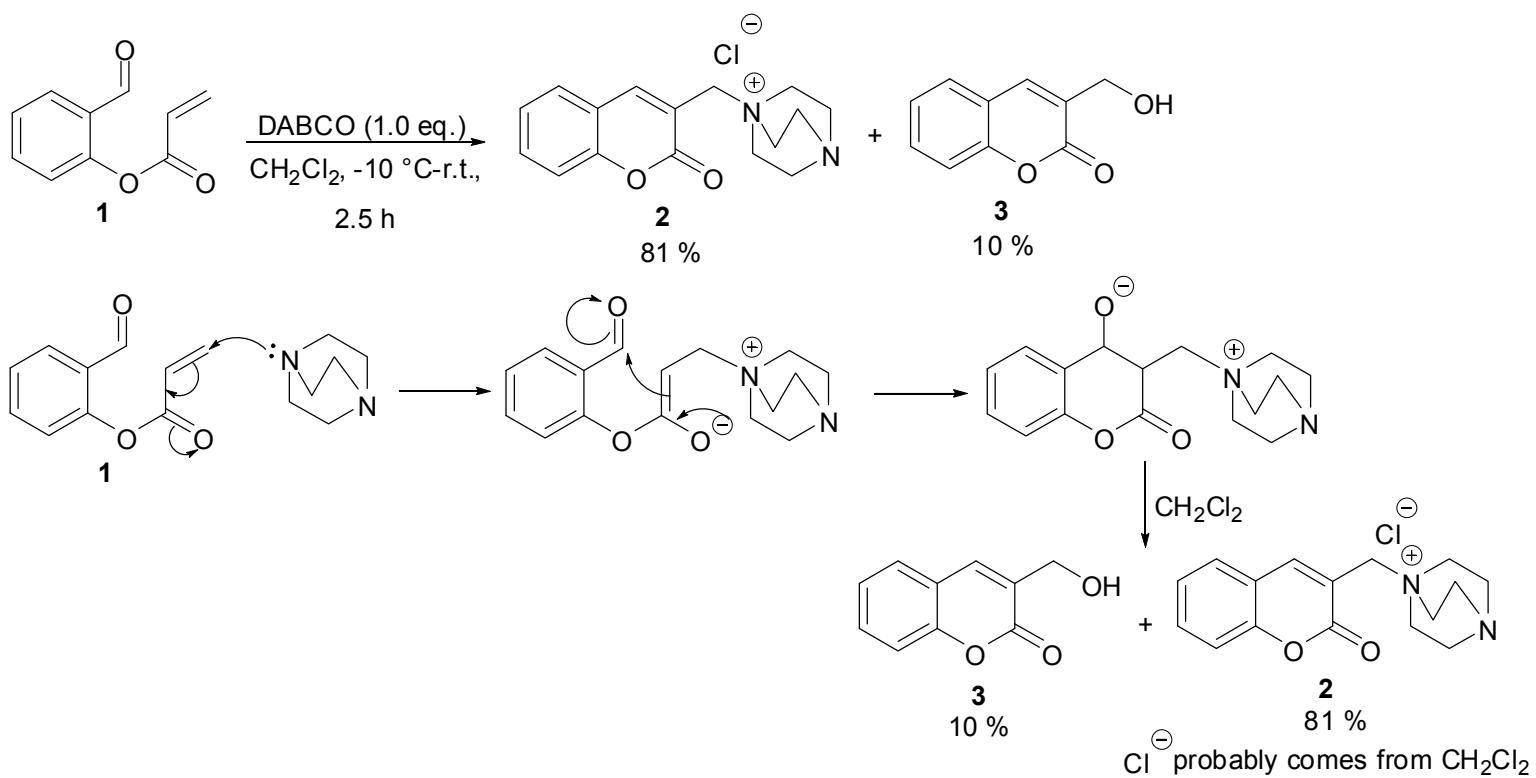

Scheme 3. IBH reaction of $\alpha, \beta$-unsaturated ester-aldehyde: synthesis of coumarin salt.

\subsection{IBH reactions: activated alkenes ( $\alpha, \beta$-unsaturated sulfonates or $\alpha, \beta$-unsaturated sulfonamides)-aldehyde system}

In 2011 Ghandi and co-workers reported ${ }^{37}$ an interesting solvent-dependant intramolecular BH reaction of 2-formylaryl-(E)-2-arylethylenesulfonates 6 which were obtained via the reaction between 2-hydroxyarylaldehydes 4 and $(E)$-2-arylethenesulfonyl chlorides $\mathbf{5}$. Reaction of $\mathbf{6}$ with DBU (cat.) in DMF as a solvent provided $\beta$-keto- $\delta$-sultone derivative $\left(R^{1}=R^{2}=H\right) 8$ while same reaction with DBU (cat.) in $\mathrm{MeOH}$ gave the ene-sultone 7 (Scheme 4). It is believed that $\beta$-keto$\delta$-sultone 8 was obtained from the $\mathrm{BH}$ adduct after isomerization involving 1,3-proton shift while the ene-sultone 7 was derived from the IBH adduct after dehydration (Scheme 4). They also observed that the reaction between 2-hydroxyarylaldehydes and (E)-2-arylethenesulfonyl chlorides under the influence of DBU (cat.) in DMF directly gave the $\beta$-keto- $\delta$-sultones 8 (Scheme 4). ${ }^{37}$

Three years later Ghandi and co-workers also reported intramolecular BH reaction of vinyl (styryl)-sulfonamide-aldehyde system 9 using DBU as a catalyst. When this reaction was performed in alcoholic solvents benzo- $\delta$-sultams $\mathbf{1 0}$ were obtained. The same reaction in DMF as solvent provided 3-benzyl-3-hydroxyoxindoles 11 (Scheme 5). ${ }^{38}$ The authors presented reasonable mechanisms for these transformations [for benzo- $\delta$-sultams 10, see Scheme 6 (Path A) and indole derivatives 11, see Scheme 7 (Path B)]. ${ }^{38}$ It seems to us that alternative Path C (Scheme 6) and Path D (Scheme 7) are also possible. 


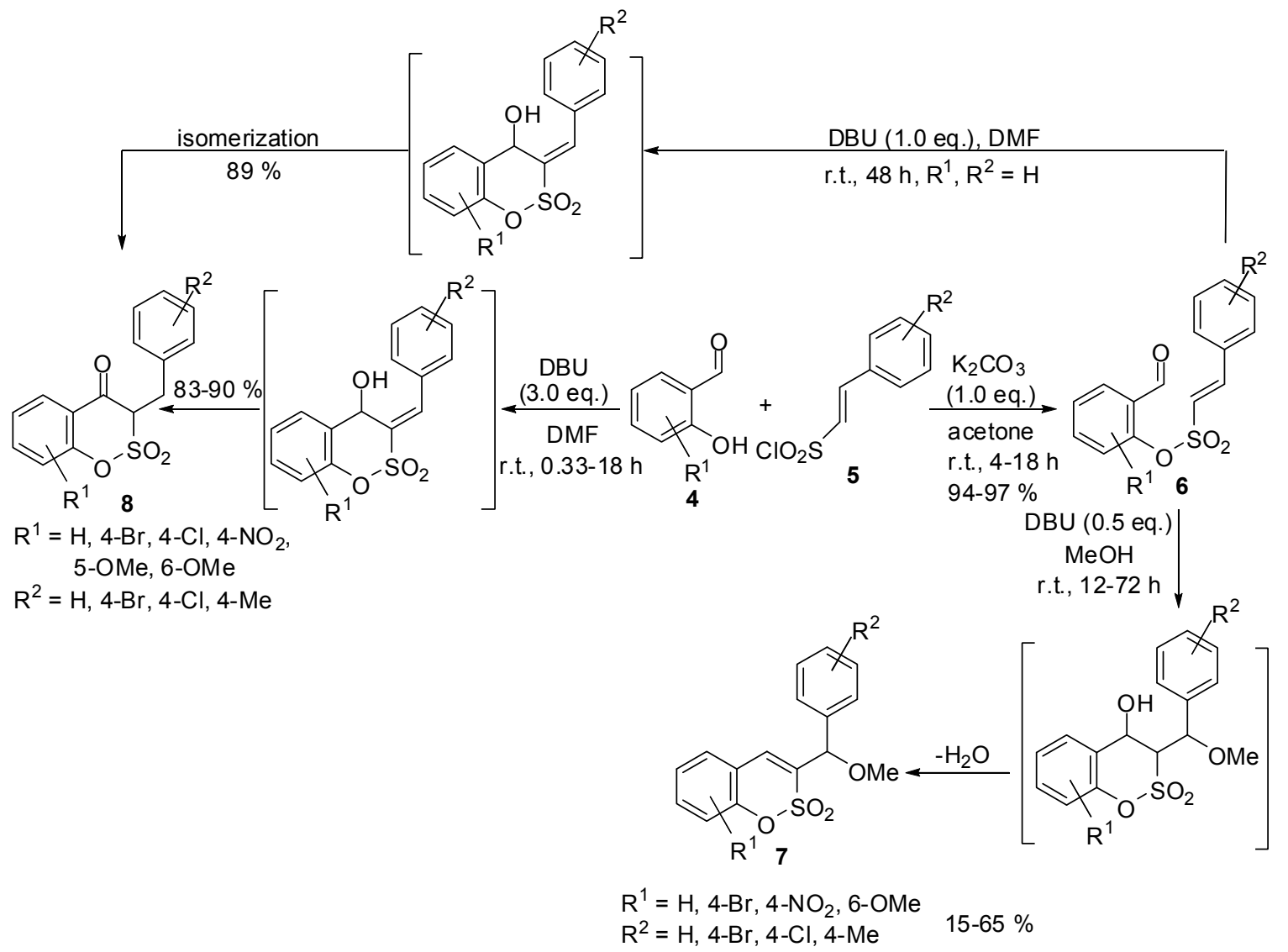

Scheme 4. IBH reaction of $\alpha, \beta$-unsaturated sulfonate-aldehyde system.<smiles>[R]c1ccc(CC2(O)C(=O)N([Y6])c3ccc([R])cc32)cc1</smiles>

$\mathrm{R}^{1}=\mathrm{H}, \mathrm{Me}, \mathrm{OMe}$ $\mathrm{R}^{2}=\mathrm{H}, \mathrm{Br}, \mathrm{Cl}$

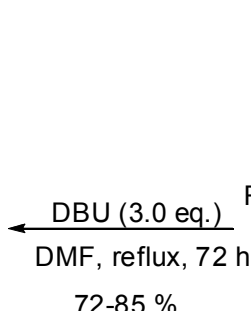

$72-85 \%$<smiles>[R]c1ccc(/C=C/[R](=O)(O)Nc2ccc([R])cc2C=O)cc1</smiles>

$\mathrm{Me}$

9<smiles></smiles>

$\mathrm{R}=\mathrm{Et} ; \mathrm{R}^{1}=\mathrm{H} ; \mathrm{R}^{2}=\mathrm{Cl} ; 88 \%$ $\mathrm{R}=\mathrm{Et} ; \mathrm{R}^{1}=\mathrm{OMe} ; \mathrm{R}^{2}=\mathrm{H} ; 90 \%$ $\mathrm{R}=\mathrm{Et} ; \mathrm{R}^{1}=\mathrm{OMe} ; \mathrm{R}^{2}=\mathrm{Cl} ; 84 \%$

Scheme 5. Intramolecular BH-reaction of vinyl (styryl)-sulfonamide-aldehyde system. 




Scheme 6. Plausible mechanisms for the formation of benzo- $\delta$-sultams $\mathbf{1 0}$.

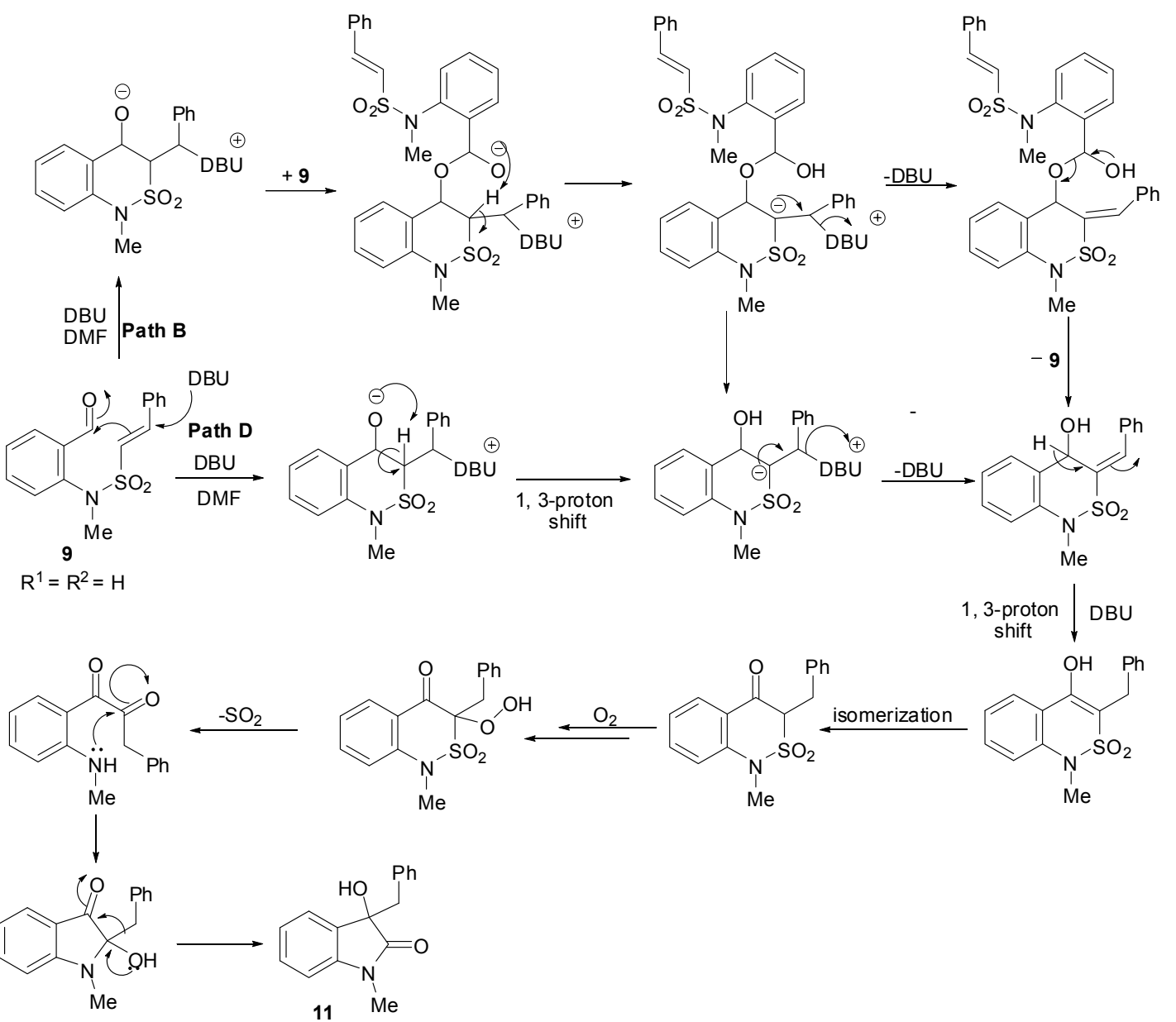

Scheme 7. Plausible mechanisms for the formation of 3-benzyl-3-hydroxyoxindoles 11. 


\subsection{IBH reactions: activated alkene ( $\alpha, \beta$-unsaturated amide)-aldehyde system}

Recently our research group has developed a facile intramolecular Baylis-Hillman reaction of the substrates 12, 13, 16 and 17 containing less reactive acrylamides as activated alkenes and aldehydes as electrophiles. This strategy provides a convenient and useful protocol for obtaining $\alpha$-methylene- $\delta$-lactam 14, $\alpha$-methylene- $\gamma$-lactam 15, and spirolactam 18 and 19 frameworks (Schemes 8 and 9). ${ }^{39}$ It is interesting to note that the reactions are faster in the case of $\mathbf{1 3}(\mathrm{n}=0)$ to provide $\alpha$-methylene- $\gamma$-lactam derivatives $\mathbf{1 5}$ in good yields, in comparison to that of $\mathbf{1 2}$ for obtaining 14.

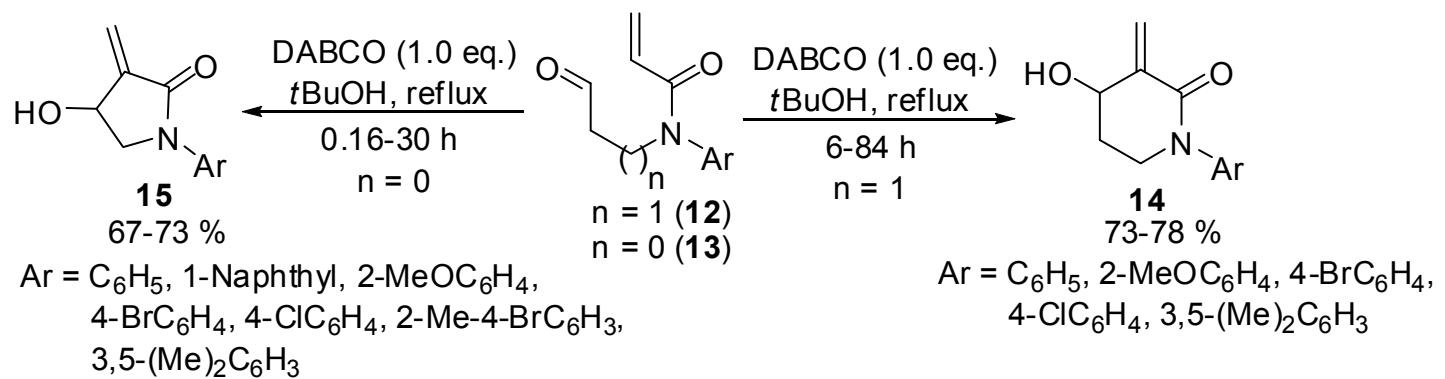

Scheme 8. IBH reaction: Synthesis of $\alpha$-methylene- $\delta$ - and $\gamma$-lactams.

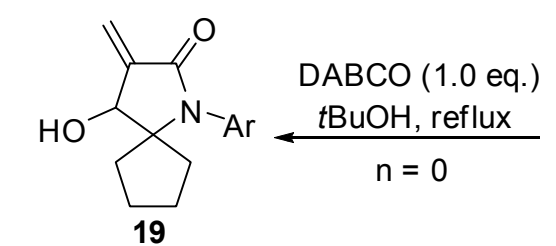

$\mathrm{Ar}=\mathrm{C}_{6} \mathrm{H}_{5} ; 2 \mathrm{~h} ; 68 \%$

$4-\mathrm{BrC}_{6} \mathrm{H}_{4} ; 0.5 \mathrm{~h} ; 70 \%$



$\mathrm{n}=1(\mathbf{1 6})$

$\mathrm{n}=0(17)$
$\mathrm{Ar}=\mathrm{C}_{6} \mathrm{H}_{5} ; 10 \mathrm{~h} ; 75 \%$

$4-\mathrm{BrC}_{6} \mathrm{H}_{4} ; 2.5 \mathrm{~h} ; 72 \%$

Scheme 9. IBH reaction: Synthesis of spirolactam frameworks.

\subsection{IBH reactions: activated alkene ( $\alpha, \beta$-unsaturated sulfonamide)-ketone system}

A few years ago Zhou and co-workers described an elegant intramolecular BH reaction of substrates (20) having a less reactive ketone as the electrophile component and an ethenylsulfonamide as the activated alkene unit, thus providing a facile synthetic strategy for obtaining five-membered ring sultams 21 according to the reaction shown in Equation $4 .{ }^{40}$ 


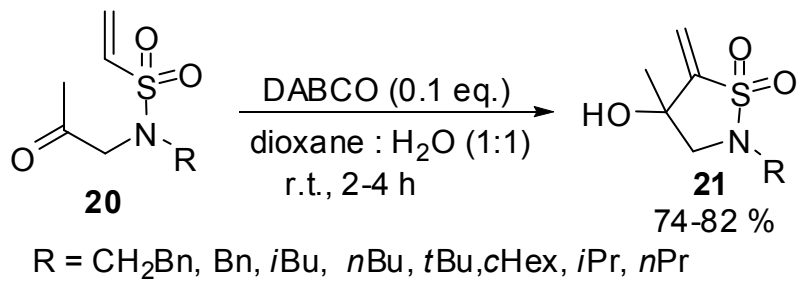

Equation 4. IBH reaction: Synthesis of $\alpha$-methylene- $\gamma$-sultams.

\subsection{IBH reactions: activated alkene ( $\alpha, \beta$-unsaturated amide)-ketone system}

Since the intramolecular BH reactions are faster in the case of acrylamide-aldehyde system $\mathbf{1 3}$ for obtaining $\alpha$-methylene- $\gamma$-lactam derivatives 15 (Scheme 8) it occurred to us that this strategy might be extended to acrylamide-ketone system 22. We were pleased to observe that these reactions were successful and provided a simple protocol for obtaining $\alpha$-methylene- $\gamma$-lactam derivatives $\mathbf{2 3}$ containing a tertiary alcoholic functionality in good yields (Equation 5). ${ }^{41}$ This study demonstrates the applicability of ketones as electrophiles in $\mathrm{BH}$ reactions if substrates are designed appropriately.<smiles>[R]C(=O)CN([R1])C(=O)C=C</smiles>

22

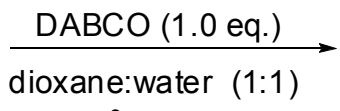

$65^{0} \mathrm{C}, 1-44 \mathrm{~h}$

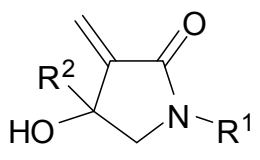

23

$\mathrm{R}^{1}=\mathrm{C}_{6} \mathrm{H}_{5}, 2-\mathrm{MeOC}_{6} \mathrm{H}_{4}, 3-\mathrm{CIC}_{6} \mathrm{H}_{4}, 4-\mathrm{BrC}_{6} \mathrm{H}_{4}, 4-\mathrm{MeC}_{6} \mathrm{H}_{4}, 3,5-\mathrm{Me}_{2} \mathrm{C}_{6} \mathrm{H}_{3}$

$\mathrm{R}^{2}=\mathrm{Me}, \mathrm{C}_{6} \mathrm{H}_{5}, 2-\mathrm{Naphthyl}, 4-\mathrm{ClC}_{6} \mathrm{H}_{4}, 4-\mathrm{MeC}_{6} \mathrm{H}_{4}$

Equation 5. IBH reaction: Synthesis of $\alpha$-methylene- $\gamma$-lactams having tertiary alcohol group.

\subsection{IBH reactions: activated alkene (vinylquinoline)-imine system}

An elegant substrate, the in situ generated vinylquinoline-imine system 24, was used as a substrate for an intramolecular BH reaction by Trifonov and co-workers. This strategy provides a simple protocol for obtaining 1',2'-dihydro-2,3'-biquinoline framework 25 (Scheme 10). ${ }^{42}$

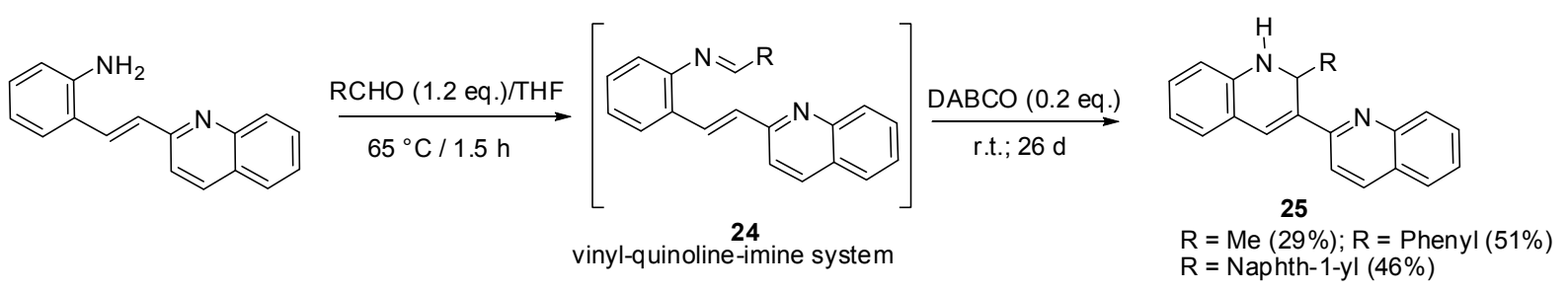

Scheme 10. IBH reaction: Synthesis of 1',2'-dihydro-2,3'-biquinoline framework. 


\subsection{Unusual-intramolecular Baylis-Hillman reaction}

An interesting intramolecular organometallic variation of $\mathrm{BH}$ reaction of substrates containing ruthenium-arene complexes (26) as an electrophile component and less reactive acrylamide as activated alkene component using tributylphosphine $\mathrm{NaH}$, providing spirolactam-ruthenium frameworks (27), was reported by Pigge and co-workers; two examples are given in Scheme 11. ${ }^{43}$ They have also performed demetallation of these products 27 using $\mathrm{CuCl}_{2}$ to provide spirocyclohex-2,5-dien-4-one derivatives 28 (Scheme 11). ${ }^{43}$ Similar treatment of enantiomerically pure acrylamide-ruthenium-arene complex 29 with tributylphosphine/ $\mathrm{NaH}$ provided the spiro compound 30 which on oxidative demetallation with $\mathrm{CuBr}_{2} / \mathrm{CO}$ gave the corresponding oxidized product 31 in enantiomerically pure form in 55\% yield (Scheme 12). ${ }^{43}$



Scheme 11. IBH reaction of acrylamide-ruthenium-arene complexes: Synthesis of spiro compounds $\mathbf{2 7}$ and $\mathbf{2 8}$.



Scheme 12. IBH reaction: Synthesis of enantiomerically pure spiropyrrolidin-2-one 31.

When Pigge and co-workers used the $\beta, \beta$-disubstituted acrylamide derivative $\mathbf{3 2}$ as a substrate the double bond migrated product $\mathbf{3 3}$ was obtained as a major compound (one example is given in Equation 6). ${ }^{43}$ Similarly in the case of substrate 34, double bond migrated product 35 was obtained exclusively (Scheme 13). ${ }^{43}$ 


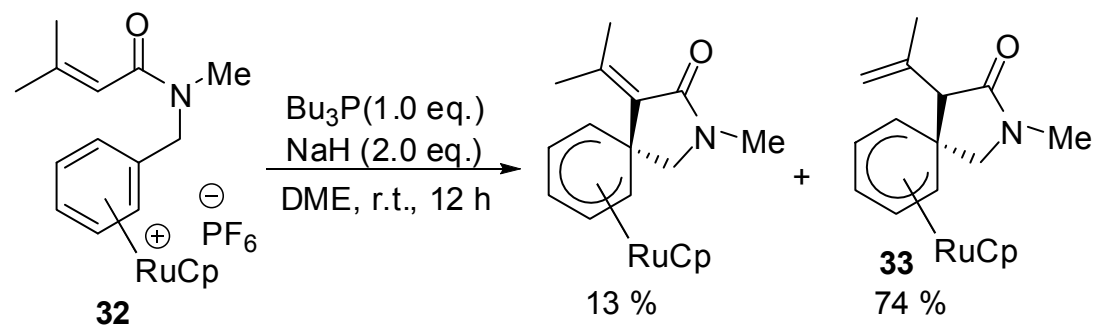

Equation 6. IBH reaction: Synthesis of spiro compound 33.<smiles>CN(Cc1ccccc1OCP)C(=O)C=C1CCCC1</smiles>

$34^{\mathrm{RuCp}}$
$\mathrm{NaH}(2.0$ eq. $)$

DME, r.t., $12 \mathrm{~h}$

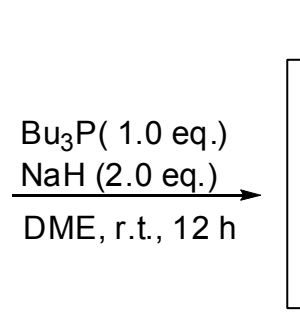

(a)

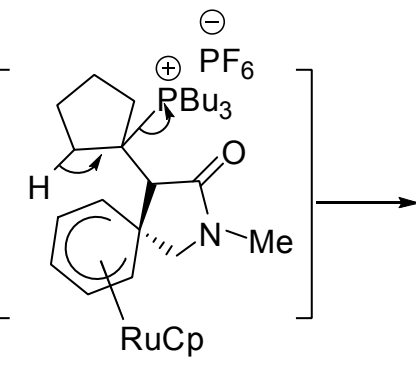

RuCp<smiles>CN1CC2(CCCC2)[C@H](C2=CCCC2)C(=O)N1C</smiles>

$35 \mathrm{RuCp}$ $69 \%$

Scheme 13. IBH reaction: Synthesis of spiro compound 35.

Pigge and co-workers subsequently extended this methodology for polycyclic systems. Two examples are presented in Scheme14. ${ }^{44}$ Treatment of acrylamide-ruthenium-arene complexes 36a and 36b with tributylphosphine/ $\mathrm{NaH}$ gave tricyclic compounds 37a and 37b which on oxidative demetallation with $\mathrm{CuBr}_{2} / \mathrm{CO}$ provided rearomatized compounds 38a and 38b respectively (Scheme 14). In all these substrates the benzylic carbon contains at least one hydrogen atom. However when they employed the substrate containing a quaternary benzylic carbon (39) they did not obtain the expected spiro product 41; instead the 3-benzazepine derivative 40 was obtained via orthocyclization (Scheme 15). ${ }^{44}$
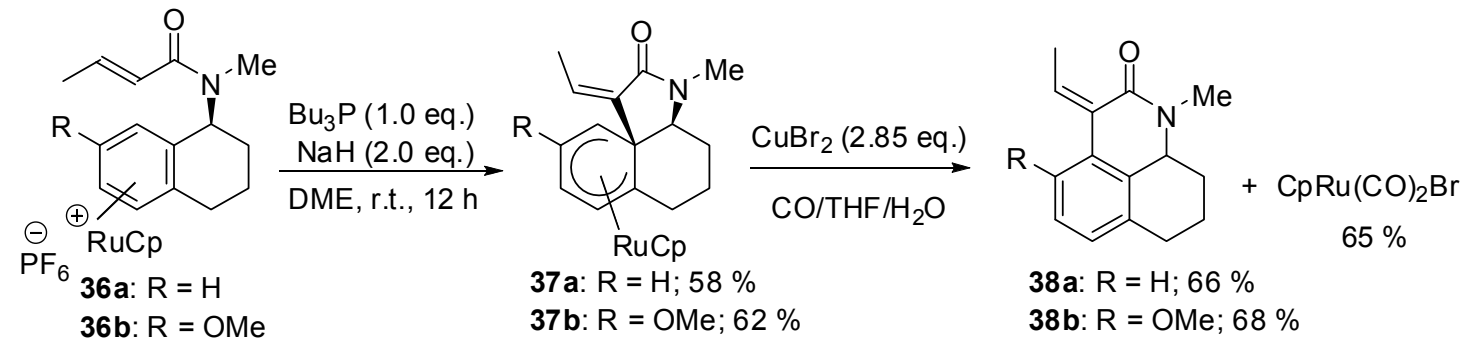

Scheme 14. IBH reaction: Synthesis of tricyclic compounds. 


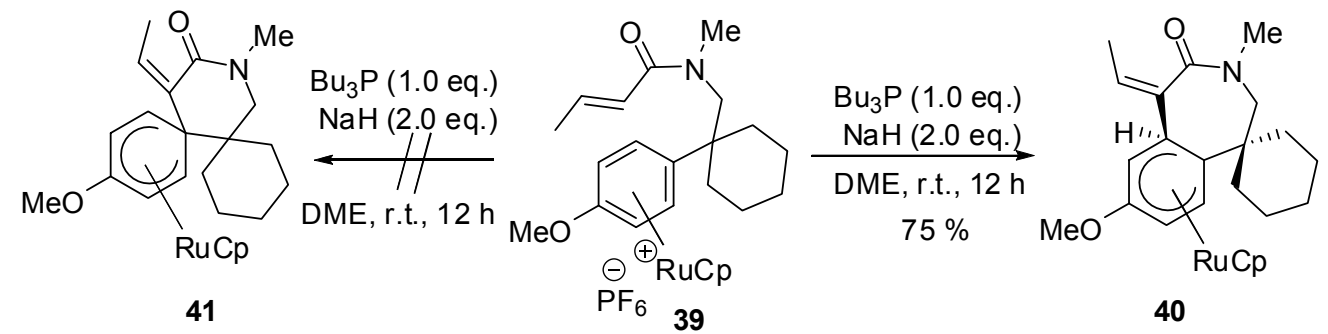

Scheme 15. IBH reaction: Synthesis of spiro compounds having a 3-benzazepine unit.

\subsection{Asymmetric intramolecular Baylis-Hillman reactions}

Asymmetric intramolecular B-H reaction can, in principle, be performed: (1) with enantiomerically pure/enriched substrates containing activated alkene and prochiral electrophile components using an appropriate (chiral / achiral) catalyst, and (2) substrates containing activated alkene and prochiral electrophile components using chiral catalyst.

2.8.1. Asymmetric IBH reactions of enantiomerically enriched/pure substrates containing activated alkene and prochiral electrophile components, using achiral catalyst. Stereoselective intramolecular BH-reaction of chiral substrate containing acrylate-aldehyde systems 42 and 44 was reported by Krishna and co-workers to provide $\alpha$-methylene furanone / pyranones $(43,45,46)$ as shown in the Equation 7 and Scheme $16 .{ }^{45}$ They also reported intramolecular BH reaction of chiral substrate having acrylamide-aldehyde unit $\mathbf{4 7}$ under the influence of $\mathrm{DABCO}$ as a catalyst to provide methyl 4-methylene-5-oxo-4,5-dihydro- $1 \mathrm{H}$ pyrrole-2-carboxylate 48 (achiral compound) (Scheme 17). ${ }^{45}$

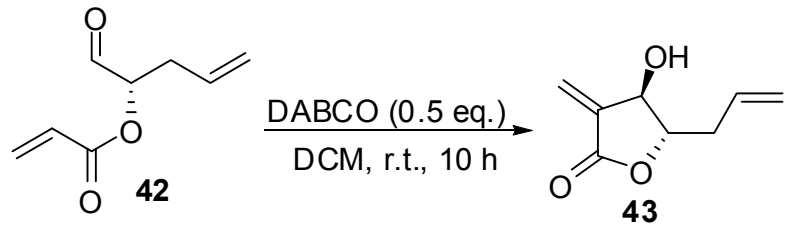

$62 \%$, de: $>95 \%$

Equation 7. IBH reaction: enantiomerically pure 42 : Synthesis of $\alpha$-methylene furanone 43.

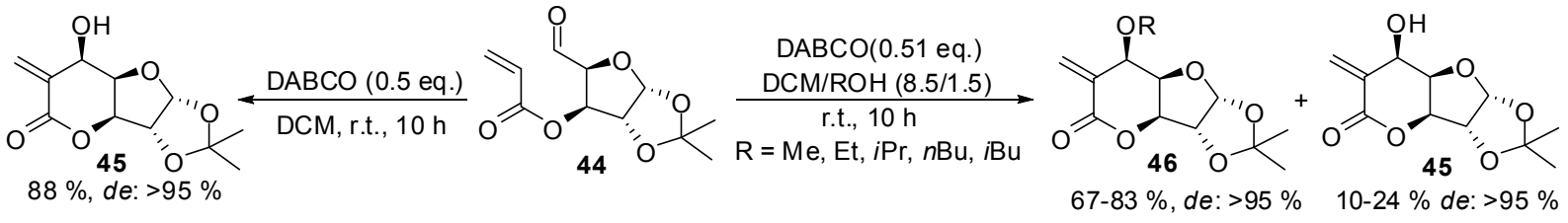

Scheme 16. IBH-reaction: enantiomerically pure 44; synthesis of $\alpha$-methylenepyran-2-ones 45 and 46. 


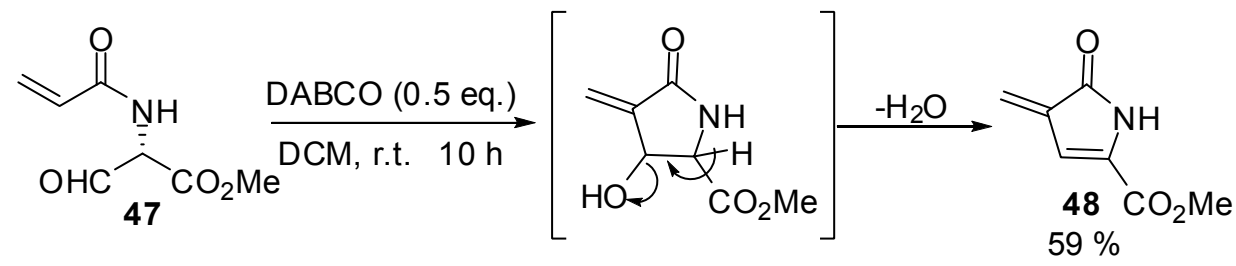

Scheme 17. IBH reaction: Enantiomerically pure acrylamide-aldehyde system 47: Synthesis of methyl 4-methylene-5-oxo-4,5-dihydro-1 $H$-pyrrole-2-carboxylate 48 (achiral compound).

A facile diastereoselective intramolecular BH-reaction of ethenylsulfonamide-carbonyl system [aldehyde $(49,52$ and 54)] derived from amino alcohols was reported by Hanson and coworkers to produce five-membered (50 and 51) (Scheme 18), ${ }^{46}$ and six-membered (53) (Scheme 19) ${ }^{47}$ ring sultams and also [5.5] bicyclic sultams (55 and 56) (Scheme 20). ${ }^{46}$ This strategy worked well also with a ketone (57) as the electrophile component to provide the [5.6] bicyclic sultam (58) (Equation 8). ${ }^{46}$

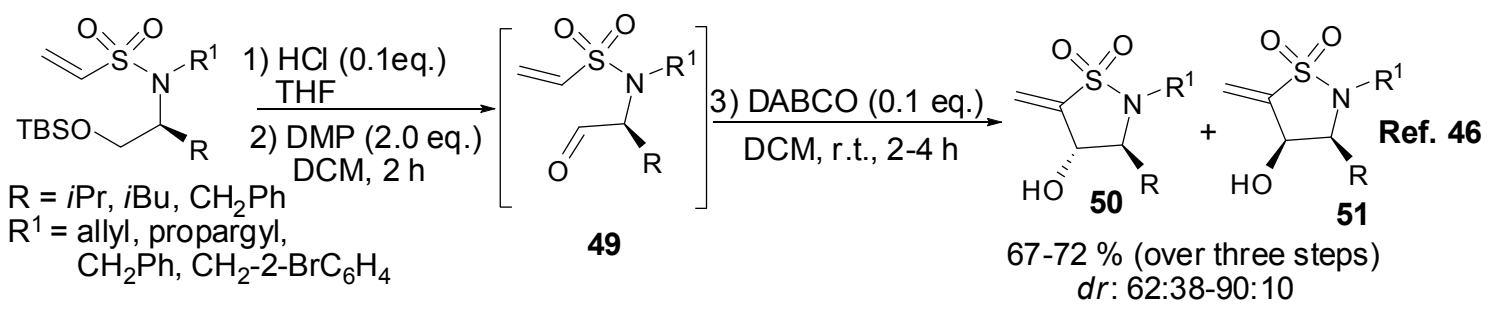

Scheme 18. IBH reaction: Synthesis of $\alpha$-methylene- $\gamma$-sultams.

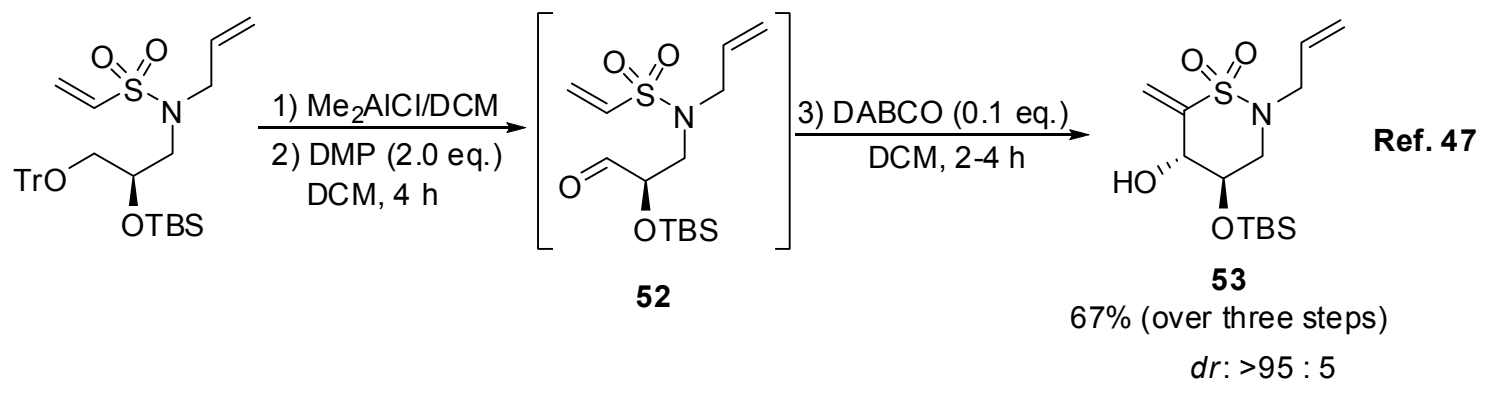

Scheme 19. IBH reaction: Synthesis of $\alpha$-methylene- $\delta$-sultam.

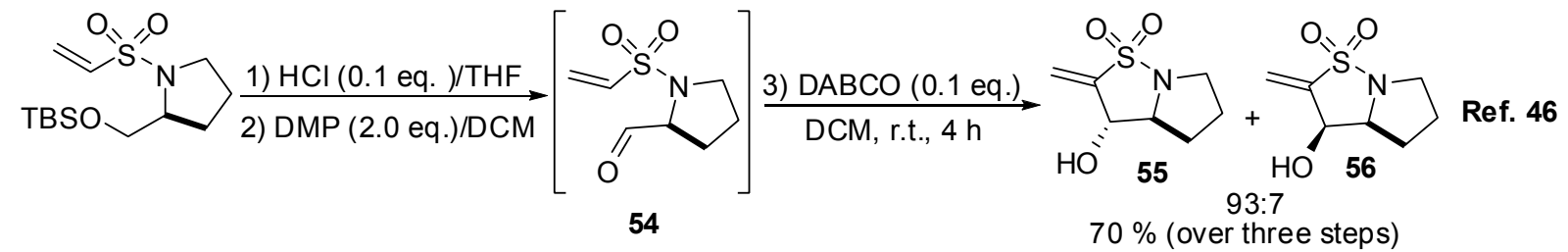

Scheme 20. IBH reaction: Synthesis of [5.5] bicyclic sultams. 


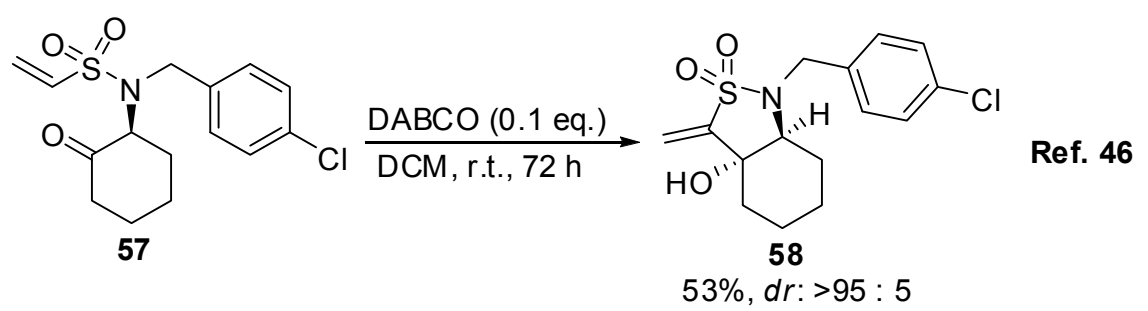

Equation 8. IBH reaction: Synthesis of [5.6] bicyclic sultam.

2.8.2. Asymmetric IBH reactions of substrates containing activated alkene and prochiral electrophile components using chiral catalyst. Our research group has examined the possibility of achieving enantioselectivity in intramolecular Baylis-Hillman reaction using quinine and quinidine as catalysts in the case of $N$-formylmethyl- $N$-phenyl acrylamide $(13, \mathrm{Ar}=$ Phenyl, $\mathrm{n}=0)$. Although the resulting $N$-phenyl-3-methylene-4-hydroxy- $\gamma$-lactam $(\mathbf{1 5}, \mathrm{Ar}=$ Phenyl, $\mathrm{n}=0)$ was obtained in low $(10 \%$ and $5 \%)$ enantioselectivities (Equation 9), this strategy certainly indicates that there is a possibility of achieving high selectivity by employing an appropriate chiral catalyst. ${ }^{39}$

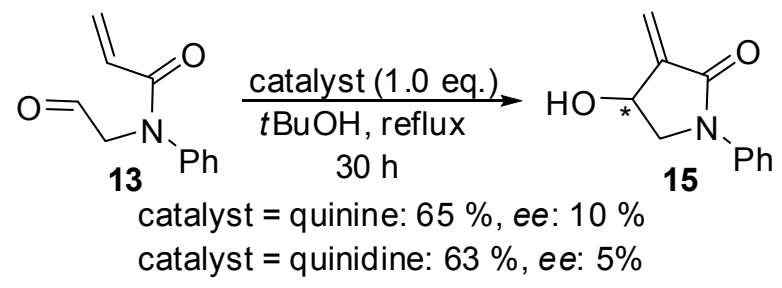

Equation 9. Asymmetric IBH reaction using quinine and quinidine as catalysts.

Unfortunately this aspect did not receive adequate attention from chemists. We are sure in the coming years it will receive the attention it deserves from synthetic chemists and grow further.

\subsection{Application to biologically active molecules and natural products}

Intramolecular asymmetric $\mathrm{BH}$ reactions providing heterocyclic compounds have been successfully employed in the synthesis of number of bioactive compounds and natural products. This section describes such applications of intramolecular BH reactions.

In 2004 Corey and co-workers ${ }^{48}$ reported a meticulous application of the intramolecular BHreaction as the key step in a total synthesis of the biologically important natural product salinosporamide A (64) using L-threonine (59) as the starting material (Scheme 21). In this strategy they employed an intramolecular BH reaction of $\mathbf{6 0}$ (substrate containing acrylamide as activated alkene component and ketone as electrophile component) in the presence of a catalytic amount of quinuclidine as the key step to provide the resulting adducts $\mathbf{6 1}$ and $\mathbf{6 2}$ in 9:1 
diastereoselectivity in $90 \%$ yield. The major compound $\mathbf{6 1}$ was selectively alkylated to provide the desired compound 63 (which was subsequently transformed into salinosporamide A 64 (Scheme 21, Path A). ${ }^{48}$ One year later Corey and co-workers came up with improved reaction conditions (Path B: titanium isopropoxide/cyclopentylmagnesium chloride/ and iodine) for performing the intramolecular BH reaction of the substrate $\mathbf{6 0}$ to produce the resulting adduct $\mathbf{6 1}$ in 99:1 diastereoselectivity (Path B, Scheme 21). ${ }^{49}$ The major compound 61 was subsequently transformed into analogue $\mathbf{6 5}$ of salinosporamide A 64 (Scheme 21, Path B). ${ }^{49}$
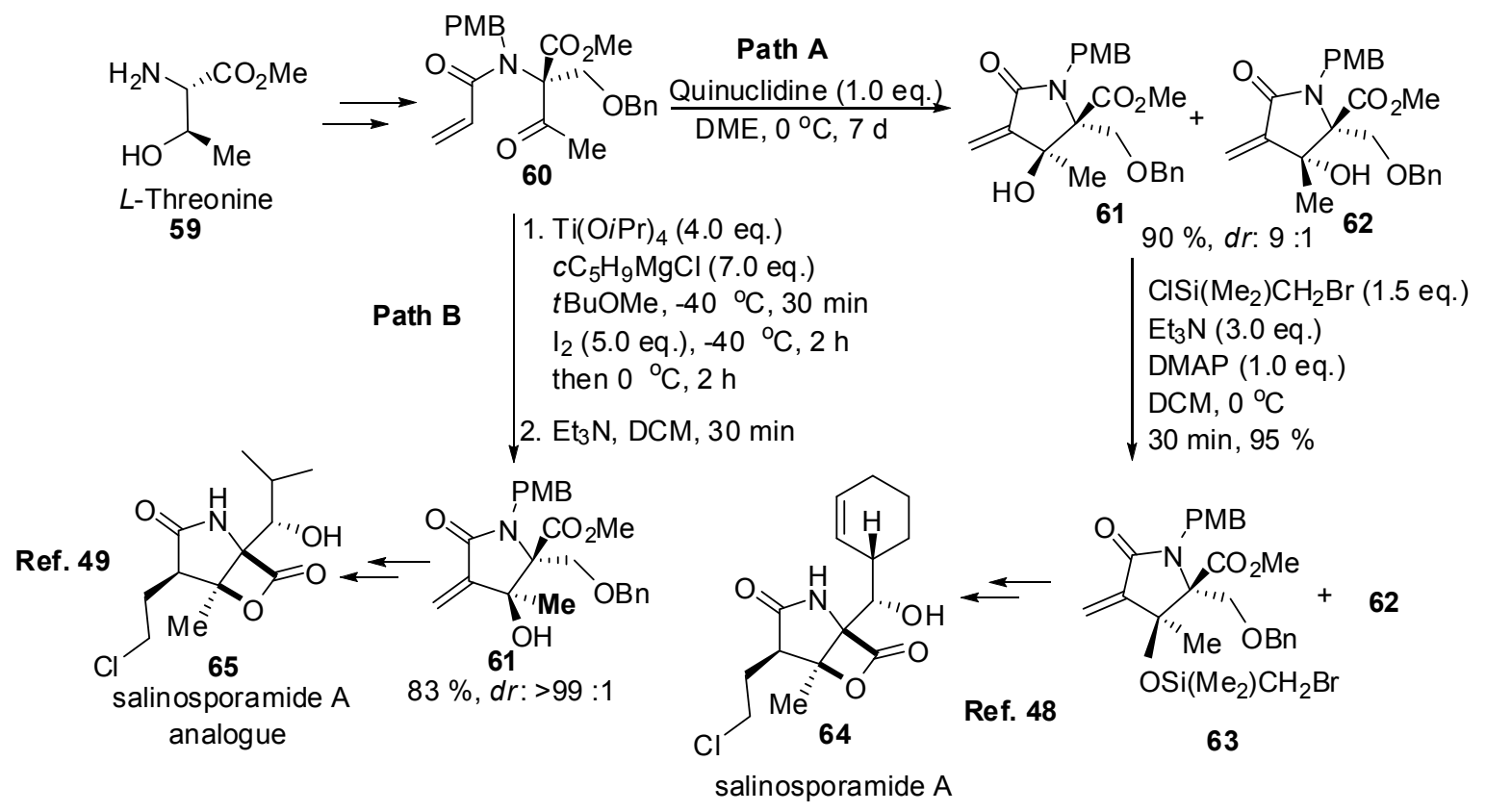

Scheme 21. IBH reaction as a key step in synthesis of salinosporamide A and its analogue.

Aggarwal and co-workers have elegantly used intramolecular Baylis-Hillman reaction as the key step in the synthesis of the natural product (+)-heliotridine $\mathbf{7 1}$ and its unnatural isomer (-)retronecine 72. Thus the IBH reaction of the in situ generated $\alpha, \beta$-unsaturated aldehyde (activated alkene component)-iminium ion (electrophilic component) system 69 using $\mathrm{TMSOTf} / \mathrm{BF}_{3} . \mathrm{OEt}_{2} / \mathrm{SMe}_{2}$ gave the $\mathrm{BH}$ adduct $\mathbf{7 0}$ which was conveniently transformed into (+)heliotridine 71 and its unnatural isomer (-)-retronecine $\mathbf{7 2}$ via the reaction with LAH following the reaction sequence illustrated in Scheme 22. ${ }^{50}$ The required in situ generated $\alpha, \beta$-unsaturated aldehyde (activated alkene component)-iminium ion system 69 was easily obtained from the corresponding precursor 68 (which was readily accessible from pyrrolidin-2-one derivative $\mathbf{6 6}$ via the treatment with acrolein using Hoveyda-Grubbs catalyst 67) following the reaction sequence shown in Scheme 22. ${ }^{50}$ 
<smiles>C=CCN1C(=O)CC(OC(C)=O)C1OCC</smiles>

66

<smiles>CCO[C@H]1[C@@H](OC(C)=O)CC(=O)N1C/C=C/C=O</smiles>

68

$74 \%$



(+)-heliotridine

(-)-retronecine

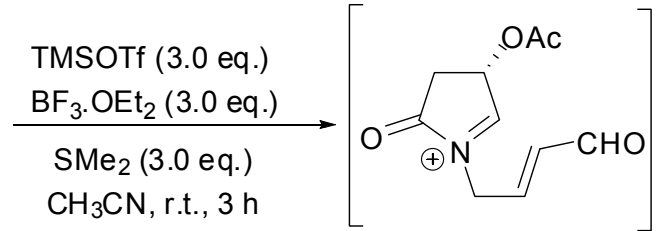

IBH-reaction

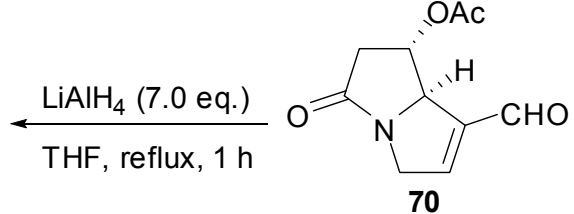

$65 \%, d r: 3: 1$

Scheme 22. IBH reaction as a key step in synthesis of (+)-heliotridine and (-)-retronecine.

Subsequently Roe and Stockman reported an intramolecular Baylis-Hillman reaction of substrates $\mathbf{7 5}$ and $\mathbf{7 6}$ (obtained from $\mathbf{7 3}$ and 74), containing $\alpha, \beta$-unsaturated ketone-iminium ion system, as a key step for synthesis of anatoxin-a $\mathrm{HCl}$ salt $\mathbf{7 7}$ and homoanatoxin- $\mathrm{HCl}$ salt $\mathbf{7 8}$, following the strategy shown in Scheme 23. ${ }^{51}$

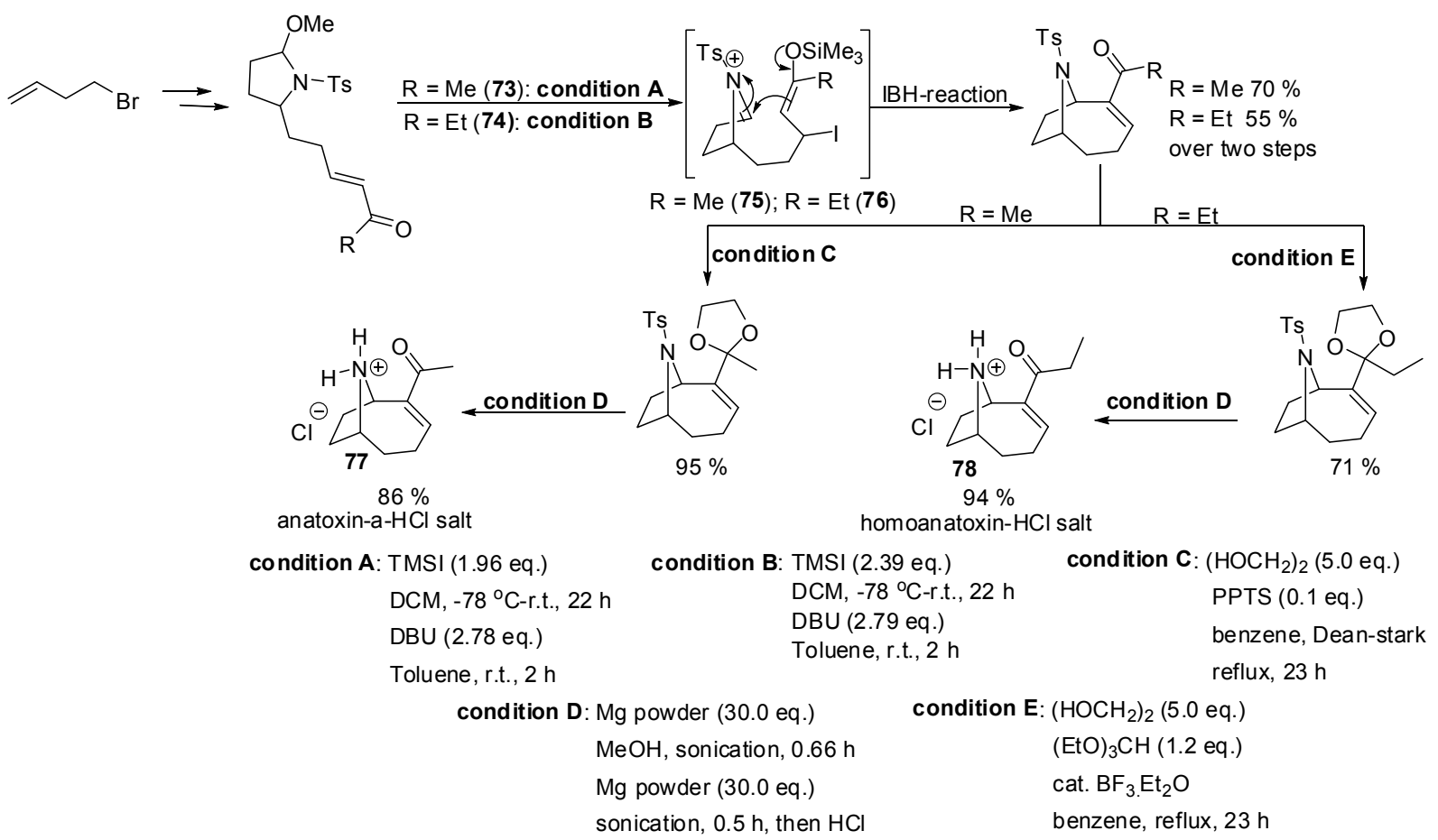

Scheme 23. IBH reaction in the synthesis of anatoxin-a and homoanatoxin hydrochlorides. 


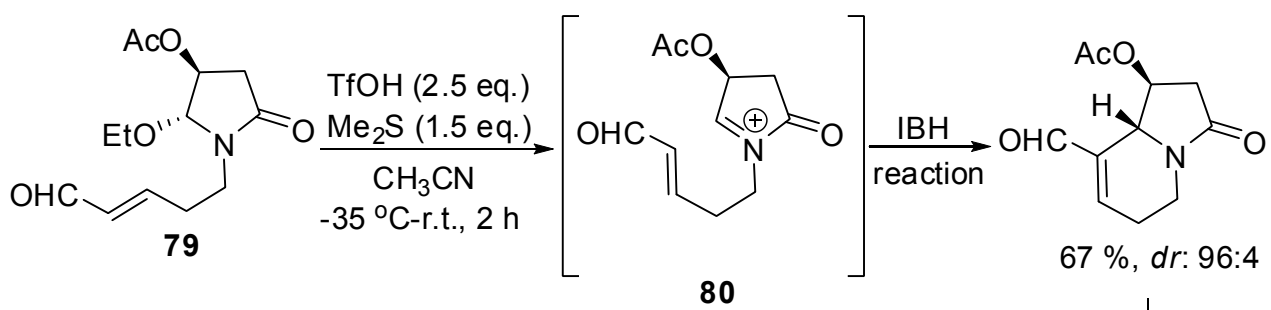

80

$67 \%, d r: 96: 4$

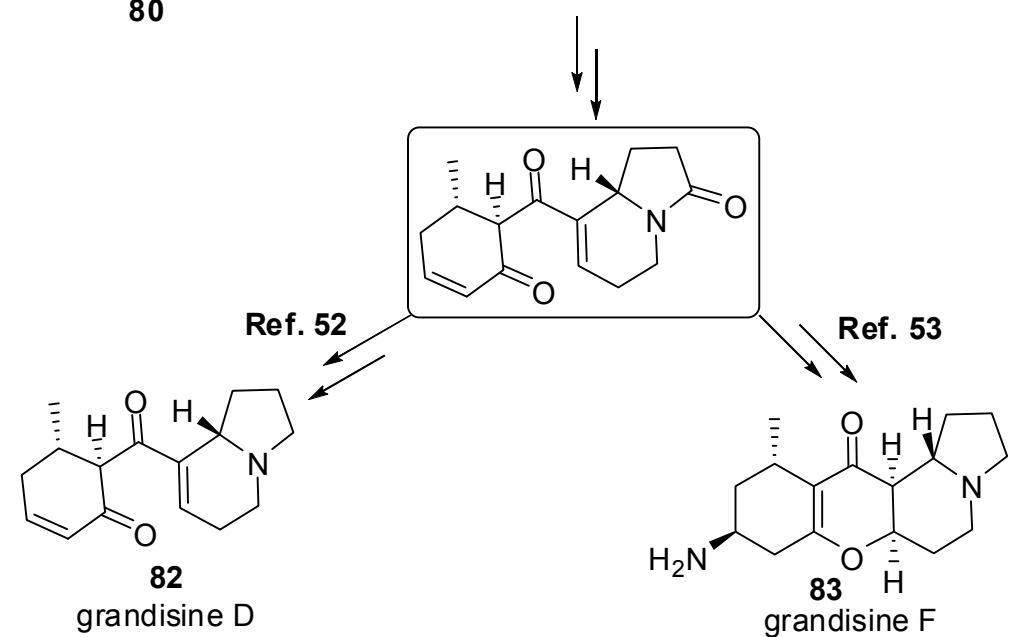

Scheme 24. IBH reaction as a key step in the synthesis of grandisines B, D and F.

Intramolecular $\mathrm{BH}$ reactions of molecule $\mathbf{8 0}$ having an $\alpha, \beta$-unsaturated aldehyde-iminium ion system has been employed by Tamura and co-workers for synthesis of the natural products/biologically active molecules grandisines $\mathrm{B}, \mathrm{D}$ and $\mathrm{F}(\mathbf{8 1}, \mathbf{8 2}$ and $\mathbf{8 3})$ according to the sequence shown in Scheme $24 .{ }^{52,53}$ The required $\alpha, \beta$-unsaturated aldehyde-iminium ion system 80 was prepared from easily accessible pyrrolidin-2-one derivative 79 (Scheme 24).

Webber and Krische ${ }^{54}$ have elegantly used intramolecular BH-reaction as the key step in formal synthesis of $( \pm$ )-quinine (Scheme 25 -Path A). Thus IBH reaction of enone (activated alkene component)-allyl carbonate (electrophilic unit) system 84 provided the corresponding product $\mathbf{8 5}$ which was conveniently transformed into Jacobsen's diene (the key intermediate for synthesis of quinine). ${ }^{55}$ They have also used the IBH product 85 in the total synthesis of $( \pm)-7$ hydroxyquinine 86 ( Scheme 25-Path B). ${ }^{54}$ 




Scheme 25. Formal synthesis of $( \pm)$-quinine and total synthesis of $( \pm)$-7-hydroxyquinine

\section{Intramolecular BH reactions (activated alkene-activated alkene system) [also known as intramolecular Rauhut-Currier (IRC) reaction]}

In the $\mathrm{BH}$ reaction, if the electrophile is also an activated alkene, then such reactions are known as Rauhut-Currier reactions. Intramolecular Rauhut-Currier reactions are well documented in the literature for obtaining carbocyclic compounds. ${ }^{15,18,31-34}$ However, very few reports have appeared for obtaining heterocyclic compounds. This section presents such examples.

Oshima and co-workers reported a facile protocol for obtaining tetrahydro- $2 \mathrm{H}$-pyran derivative 88 with high stereoselectivity via intramolecular vinylogous Baylis-Hillman (Rauhut-Currier) reaction of substrate 87 (containing enone-enone system) using $\mathrm{TiCl}_{4} / n \mathrm{Bu}_{4} \mathrm{NI}$ as shown in Equation $10 .^{56}$

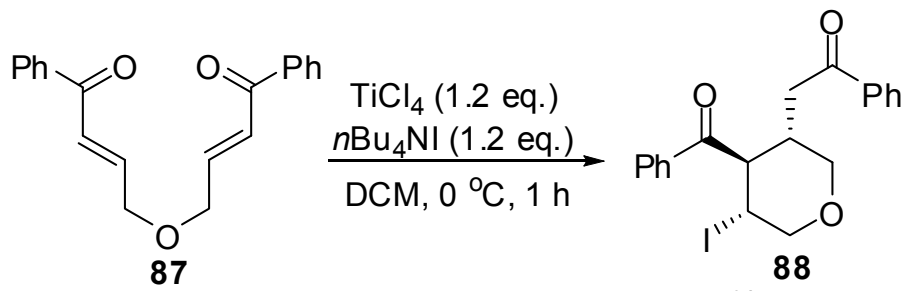

Equation 10. Intramolecular Rauhut-Currier reaction (IRC reaction) of enone-enone system. 
Tributylphosphine catalyzed intramolecular Baylis-Hillman (intramolecular Rauhut-Currier) (IRC) reaction of enone-enone systems $\mathbf{8 9}$ and $\mathbf{9 0}$ was reported by Krische and co-workers to provide tetrahydropyran and piperidine derivatives $\mathbf{9 1}$ and $\mathbf{9 2}$ respectively following the reaction sequence as shown in Equation 11. ${ }^{57}$



Equation 11. IRC reaction of enone-enone systems.

A highly reactive enal was utilized as the activated alkene component for coupling with eneester as electrophile component (as shown in compound 93) in an intramolecular Rauhut-Currier reaction by Roush and co-workers, thus providing an interesting strategy for obtaining the 2,5dihydrofuran derivative 94 (Equation 12). ${ }^{58}$

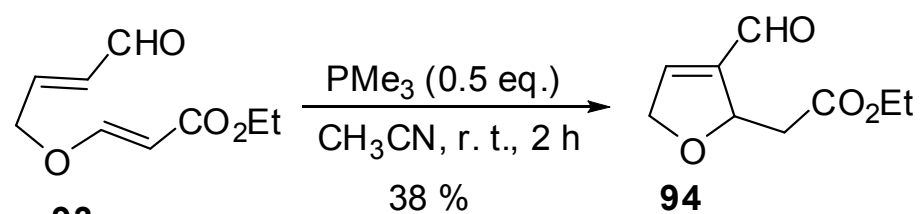

93

$38 \%$

94

Equation 12. IRC reaction of enal-enoate system: synthesis of 2,5-dihydrofuran derivative.

Luis and Krische reported a facile chemoselective intramolecular Rauhut-Currier reaction of vinyl thiolate (as activated alkene component)-vinyl sulfone (as electrophile component) system 95 under the catalytic influence of tributylphosphine for obtaining piperidine derivative $\mathbf{9 6}$ as shown (Equation 13). ${ }^{59}$<smiles>CCC(=O)/C=C/CN([13CH3])/C=C/S(=O)(=O)c1ccc([N+](=O)[O-])cc1</smiles>

Equation 13. Chemoselective IRC reaction of vinyl thiolate-vinyl sulfone system 95. 


\subsection{Asymmetric intramolecular Rauhut-Currier reactions}

A convenient procedure for the synthesis of 2-(3-nitro- $2 H$-chromen-2-yl)acetate 101 and 2-(3nitro- $2 H$-thiochromen-2-yl)acetate derivatives 102 in high enantioselectivities via asymmetric intramolecular Rauhut-Currier reaction of $\mathbf{9 7}$ and 98 respectively using a chiral catalyst $\mathbf{1 0 0}$ (in the presence of 99) was reported by Xiao and co-workers (Equation 14). ${ }^{60}$
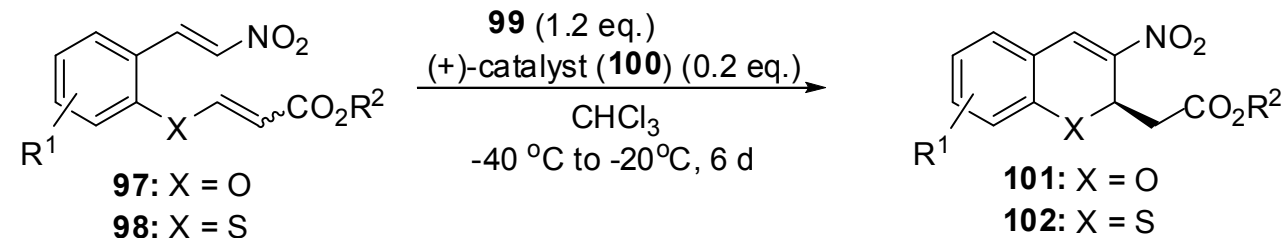

$\mathrm{R}^{1}=\mathrm{H}, 4-\mathrm{Me}$, 4-OMe, 5-OMe, 4-F, 4-Cl, 4-Br

$\mathrm{R}^{2}=\mathrm{Me}, \mathrm{Et}$

$74-98 \%$, ee: $73-98 \%$

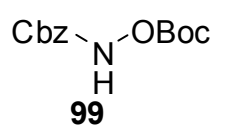

$(+)$-catalyst $=$

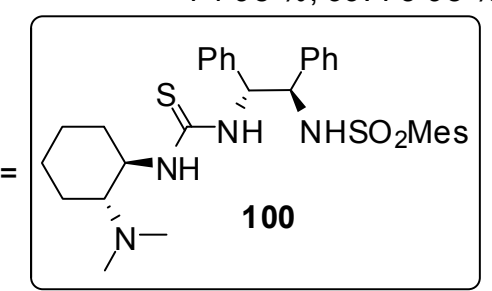

Equation 14. Asymmetric IRC reaction of $\alpha, \beta$-unsaturated nitro- $\alpha, \beta$-unsaturated esters using chiral thiourea $\mathbf{1 0 0}$ as a catalyst.

Sasai and co-workers have used chiral phosphine catalysts 104 for highly diastereo- and enantio-selective intramolecular Rauhut-Currier reaction of $\mathbf{1 0 3}$ for obtaining $\alpha$-alkylidene- $\gamma$ butyrolactones 107 (Scheme 26, Path A). ${ }^{61}$ Subsequently Zhang and coworkers utilized phosphine catalysts 105 and 106 for similar enantioselective Rauhut-Currier reaction (Scheme 26, Paths B and C) of $\mathbf{1 0 3}$ to provide the resulting adducts $\mathbf{1 0 7}$ in high enantioselectivities. ${ }^{62}$ Sasai and coworkers also used trimethylated compound 108 for Rauhut-Currier reaction under similar conditions to provide the resulting $\alpha$-alkylidene- $\gamma$-butyrolactone $\mathbf{1 0 9}$ in $70 \%$ ee (Scheme 27, Path A). ${ }^{61}$ When the same reaction was performed in the presence of Brønsted acid (BA) (2-naphthol) the resulting bicyclic compound 109 was obtained in $93 \%$ ee (but in $38 \%$ yield) (Scheme 27, Path B). ${ }^{63}$ It is interesting to note that the Zhang's catalyst $\mathbf{1 0 5}$ provided better selectivities for intramolecular Rauhut-Currier reaction of $\mathbf{1 0 8}$ thus producing the resulting adduct 109 in $98 \%$ ee and in high yield (89\%) (Scheme 27, Path C). ${ }^{62}$ 

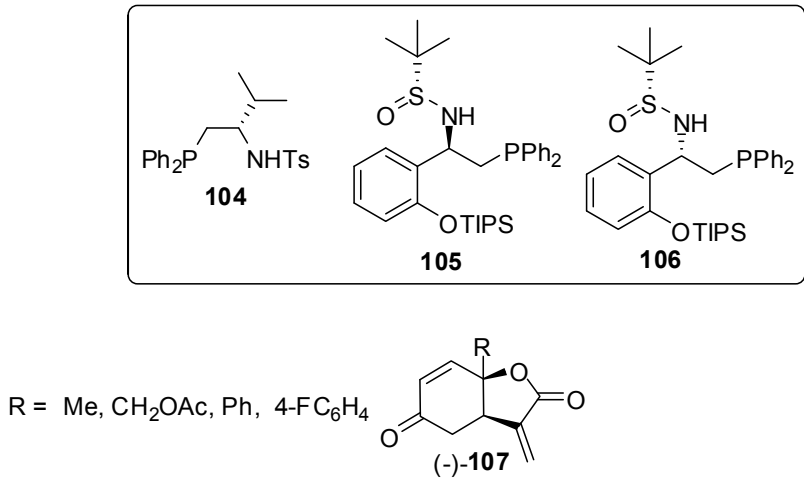

83-91\%, ee: $81-86 \%$

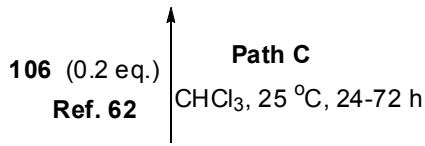

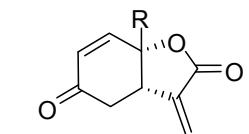

(+)-107

81-95\%, ee: 96-99 \%

$\mathrm{R}=\mathrm{Me}, \mathrm{Et}, n \mathrm{Bu}, n \mathrm{Pr}, \mathrm{CH}_{2} \mathrm{OAc}, \mathrm{CH}_{2} \mathrm{CH}_{2} \mathrm{CO}_{2} \mathrm{Me}$,

$\mathrm{Ph}, 4-\mathrm{BrC}_{6} \mathrm{H}_{4}, 4-\mathrm{FC}_{6} \mathrm{H}_{4}, 3,4,5-\mathrm{F}_{3} \mathrm{C}_{6} \mathrm{H}_{2}$

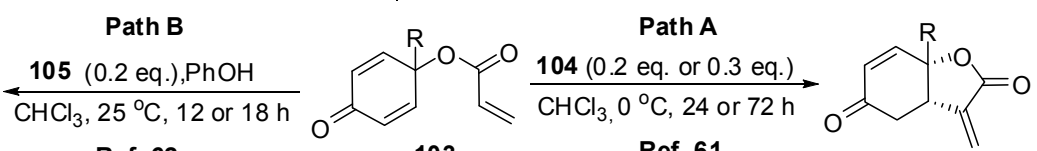

103

Ref. 61

(+) -107 $71-99 \%$, ee: $90-98 \%$ $\mathrm{R}=\mathrm{Me}, \mathrm{Et}, n \mathrm{Bu}, \mathrm{CH}_{2} \mathrm{OAc}, \mathrm{CH}_{2} \mathrm{CH}_{2} \mathrm{CO}_{2} \mathrm{Me}$, $\mathrm{Ph}, 4-\mathrm{BrC}_{6} \mathrm{H}_{4}, 4-\mathrm{MeC}_{6} \mathrm{H}_{4}, 3,5-\left(\mathrm{CF}_{3}\right)_{2} \mathrm{C}_{6} \mathrm{H}_{3}$, $3,4,5-\mathrm{F}_{3} \mathrm{C}_{6} \mathrm{H}_{2}$

Scheme 26. Asymmetric IRC reaction of acrylate-enones using chiral phosphines 104-106 as catalysts.

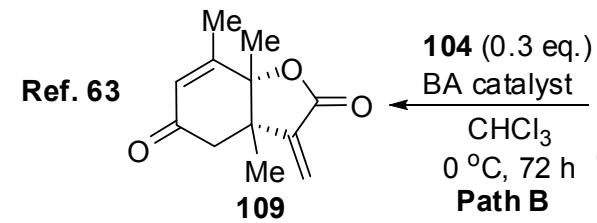

BA catalyst $=2-$ Naphthol ( 0.3 eq.), $38 \%$, ee: $93 \%$<smiles>C=CC(=O)OC1(OC)C(C)=CC(=O)C=C1C</smiles>

105 (0.2 eq.) $\mathrm{CHCl}_{3}, 25^{\circ} \mathrm{C}, 72 \mathrm{~h}$

Path C

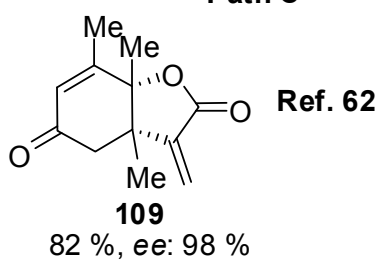

Scheme 27. Asymmetric IRC reaction of acrylate-enone 108.

Very recently Spring and co-workers have utilized peptidic phosphine $\mathbf{1 1 1}$ and sulfonamide phosphine 104 as chiral catalysts for asymmetric intramolecular Rauhut-Currier reaction of acrylate-enones $\mathbf{1 1 0}$ for the synthesis of chromanone derivatives $\mathbf{1 1 2}$ in good enantioselectivities 
as shown in the Equation $15 .{ }^{64}$ It is interesting to note that when $\mathrm{R}$ is 4-nitro group in $\mathbf{1 1 0}$ no reaction occurred in the case of both the catalysts.
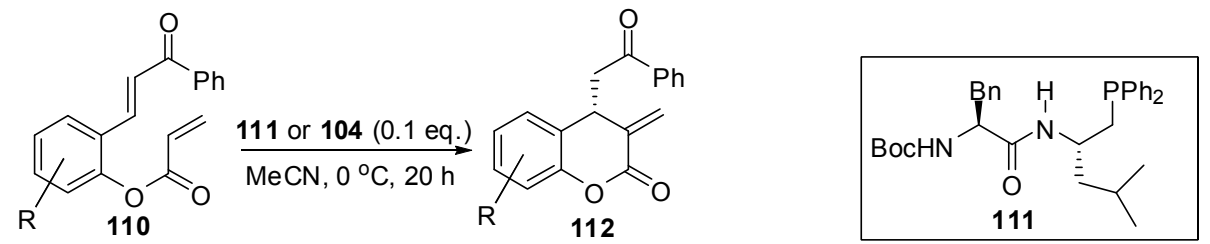

cat. 111:50-99\%, ee: $50-99 \%$

cat. 104: $65-99 \%$, ee: $79-86 \%$

$\mathrm{R}=\mathrm{H}, 4-\mathrm{Br}, 6-\mathrm{CH}_{2}-\mathrm{CH}=\mathrm{CH}_{2}, 4-\mathrm{Cl}, 4-\mathrm{F}, 4-\mathrm{Me}, 4-\mathrm{MeO}, 4,6-(t \mathrm{Bu})_{2}, 3,5-(\mathrm{Cl})_{2}$

Equation 15. Asymmetric IRC reaction of acrylate-enones 110.

It is quiet fascinating to note that $\mathrm{Chi}$ and co-workers ${ }^{65}$ have proposed an interesting reaction pathway (a plausible mechanism-Scheme 28) involving intramolecular Rauhut-Currier reaction in their work on chiral phosphine (104) catalyzed enantioselective intramolecular [2+4] annulation of acrylate- $\alpha, \beta$-unsaturated imine systems (113), providing tricyclic heterocyclic compounds (114) in high diastereo and enantio selectivities (Equation 16). In fact, in order to prove the mechanism proposed, they isolated the intramolecular Rauhut-Currier adduct 115 using triphenylphosphine as a catalyst. ${ }^{65}$

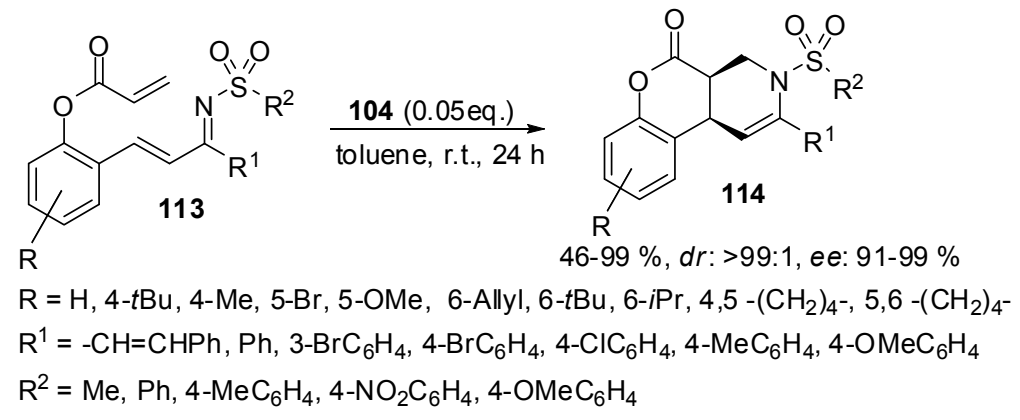

Equation 16. Asymmetric [2+4] annulation of acrylate- $\alpha, \beta$-unsaturated imine systems 113. 


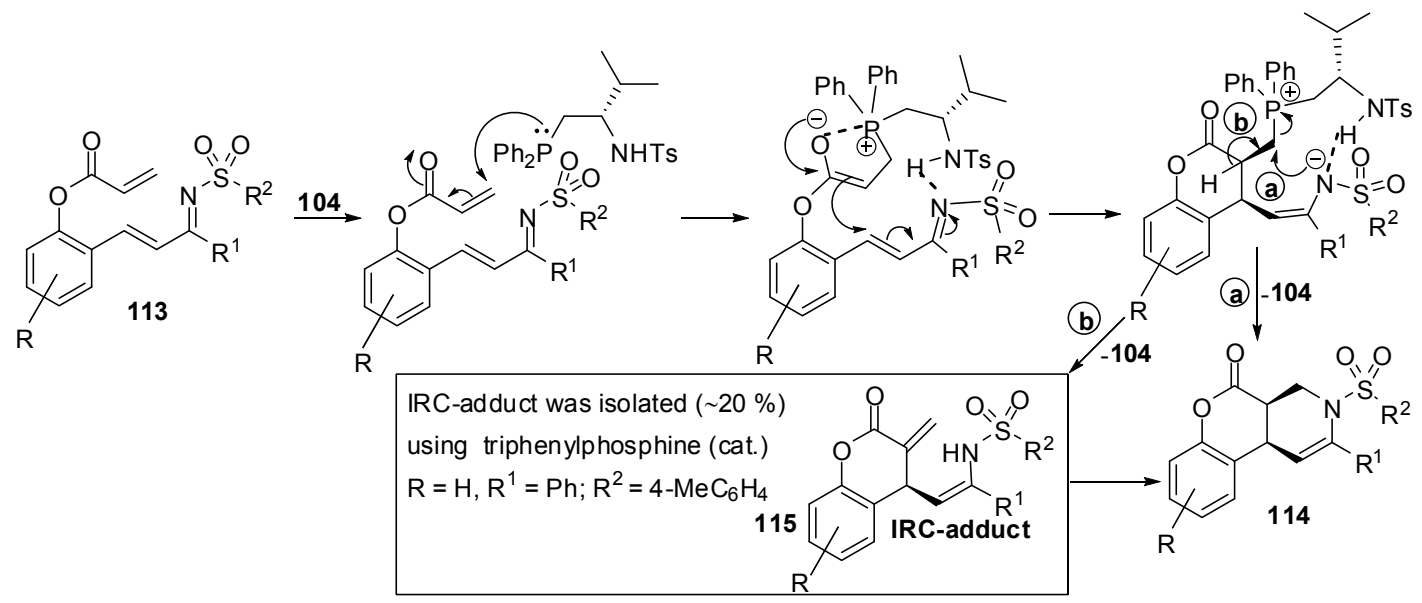

Scheme 28. A plausible mechanism involving intramolecular Rauhut-Currier reaction in the synthesis of tricyclic compounds 114.

\subsection{Applications of intramolecular Rauhut-Currier reactions}

Roush and co-workers reported an elegant synthesis of (-)-spinosyn-A 116 and its analogue spinosyn-A pseudoaglycon 117 using intramolecular BH-(intramolecular Rauhut-Currier) reaction as a key step (Scheme 29). ${ }^{66,67}$ The IRC reaction of $\mathbf{1 1 8}$ provided the corresponding adduct 119 as the major product along with two minor products 120 and $\mathbf{1 2 1}$. The major product was transformed into (-)-spinosyn-A 116 and its analogue spinosyn-A pseudoaglycon 117 following the reaction strategy as shown in Scheme 29. ${ }^{66,67}$ 


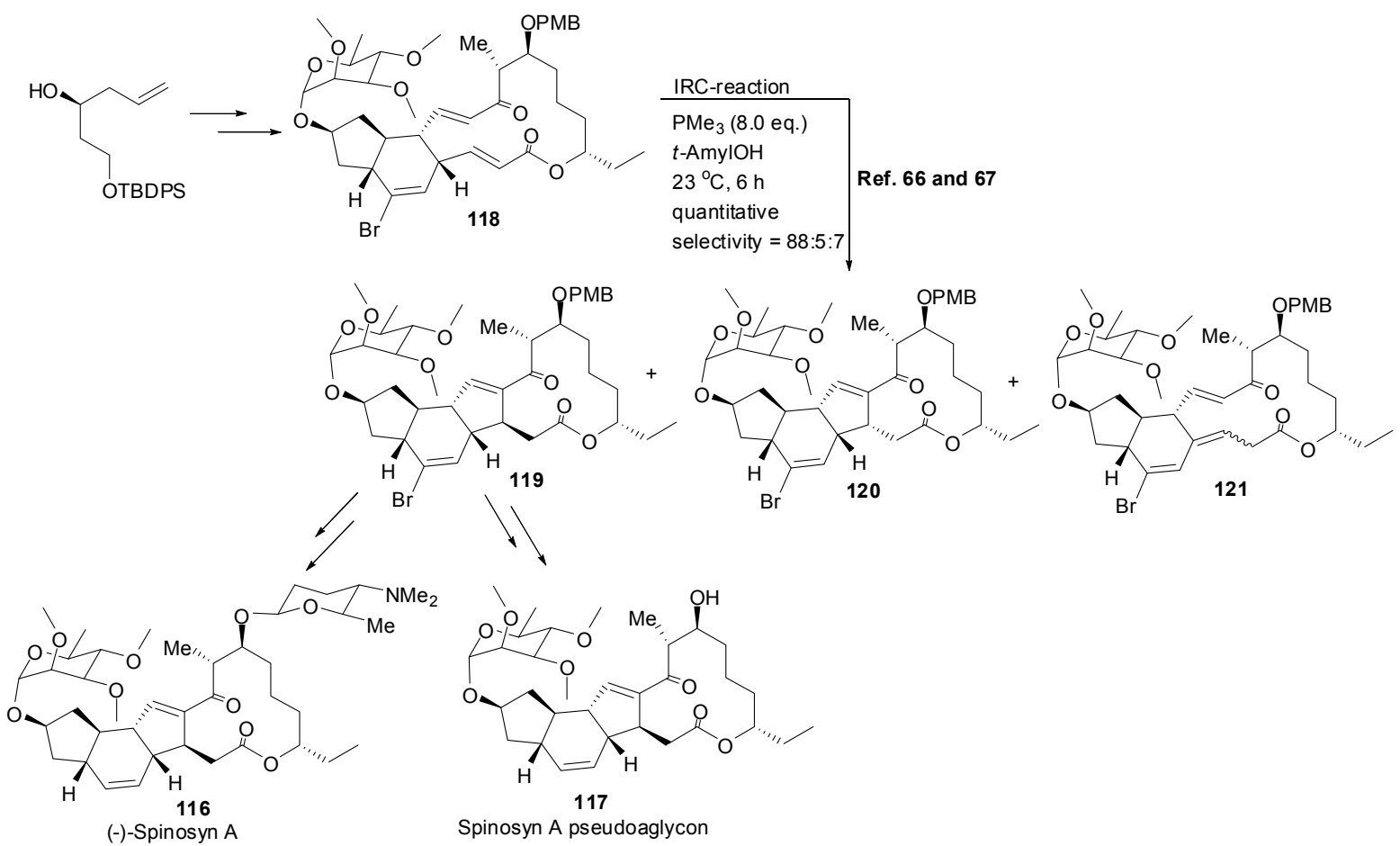

Scheme 29. Synthesis of (-)-spinosyn-A and its analogue spinosyn-A pseudoaglycon.

It is interesting to note the elegant work of Ruszczycky, Choi and co-workers who demonstrated the involvement of Rauhut-Currier reaction as the key step for the formation of tetracyclic core $\mathbf{1 2 3}$ from the tricyclic unit $\mathbf{1 2 2}$ under the influence of coenzyme $S p n L$ in biosynthetic pathway of spinosyn-A (116) (Scheme 30). ${ }^{68}$



Scheme 30. Biosynthetic pathway of spinosyn-A: IRC-reaction as the key step. 
Miller and coworkers have used intramolecular Rauhut-Currier reaction of enone-ene-esters 124 and 125 as the key step for the formation of bicyclic framework during the total synthesis of natural product Sch-642305 (126) and related analogs (127 and 128). It is fascinating to notice that these workers also examined the application of cysteine based catalyst in the RauhutCurrier reaction (Scheme 31). ${ }^{69}$

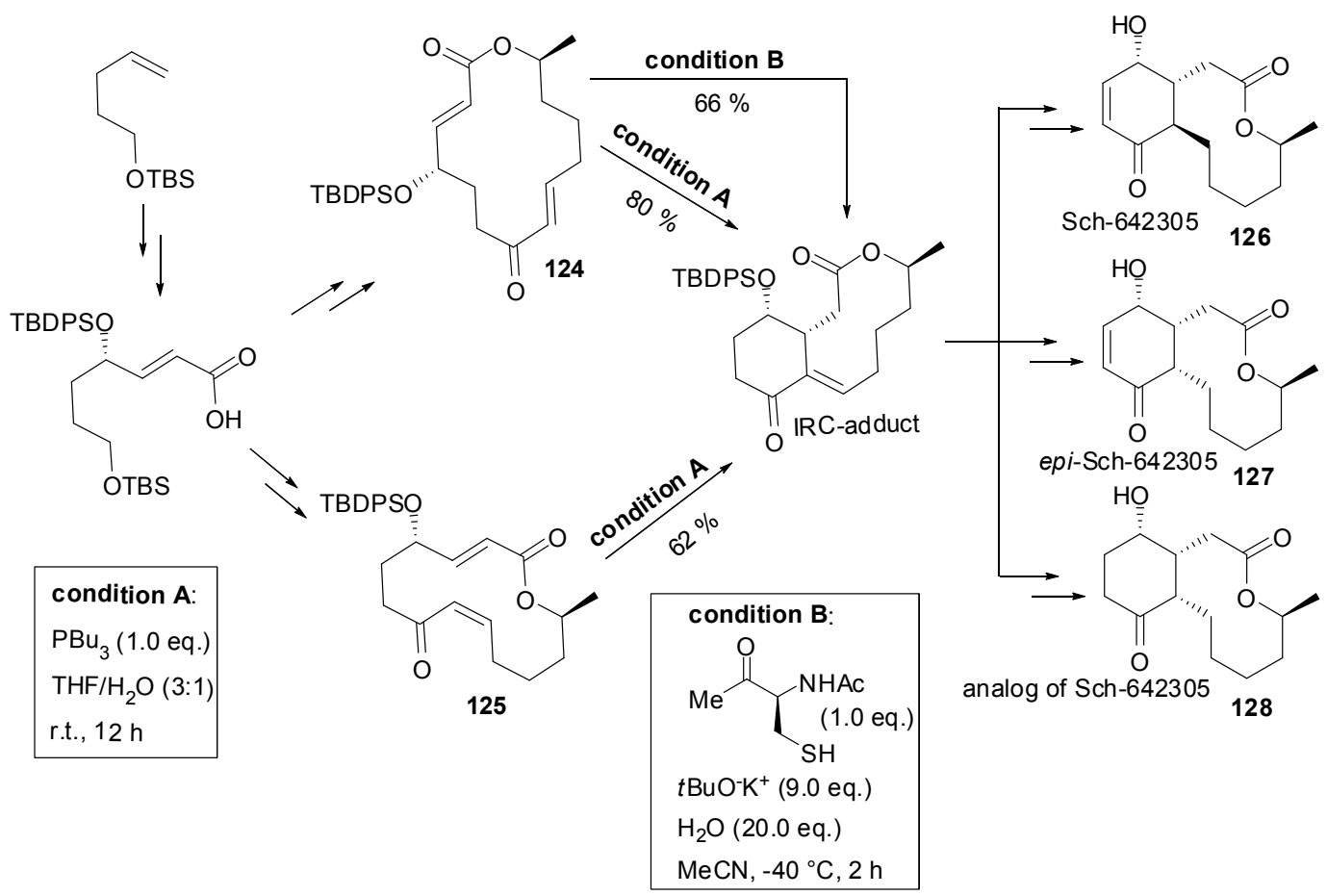

Scheme 31. Total synthesis of natural product Sch-642305 and analogs: IRC-reaction as the key step.

\section{Future Challenges and Projections}

Although there are not many publications so far on the applications of intramolecular BaylisHillman reaction for obtaining heterocyclic compounds, from this brief review it is quite clear that it is an extremely convenient and useful protocol for the synthesis of heterocyclic compounds containing oxygen, nitrogen or sulfur. Literature survey also clearly shows that in comparison to the utility of intramolecular Baylis-Hillman reaction for obtaining carbocyclic systems, such reactions for the synthesis of heterocyclic compounds have not been systematically explored, and only a few synthetic protocols have been reported for $5 / 6$ membered heterocyclic compounds. If substrates are designed appropriately it is possible to synthesize any heterocyclic compounds (including medium and large rings) of medicinal relevance. Thus this strategy offers many opportunities and challenges to the synthetic heterocyclic chemists. The 
asymmetric version is yet another challenge. There are a few reports on asymmetric intramolecular BH reactions and several aspects have not been yet explored. This is indeed a present day requirement and challenge. We predict that during the coming ten years this aspect will be followed up and exciting results will be obtained. There is also the possibility to use this strategy (both achiral and chiral versions) for the synthesis of heterocyclic compounds with two or more hetero atoms. This aspect has not so far been considered seriously and it can be expected that it will also receive appropriate attention in the coming years and fascinating results can be predicted. There is unexplored possibility of synthesizing spiro compounds $\mathbf{1 3 0}$ using two intramolecular BH reactions of 129 (Equation 17). This needs to be addressed in the coming years. Thus, the intramolecular $\mathrm{BH}$ reaction offers unending opportunities for designing strategies for obtaining heterocyclic compounds.

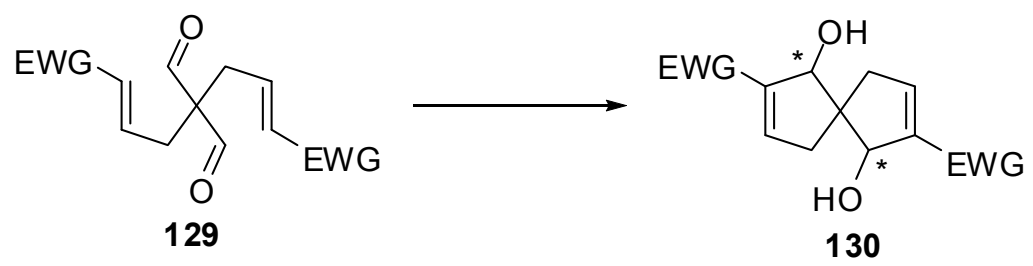

Equation 17. Two intramolecular BH reactions: synthesis of spiro compounds.

\section{Conclusions}

From this brief review it is quite clear that although intramolecular Baylis-Hillman reaction provides important classes of useful heterocyclic compounds of medicinal relevance, this aspect has not received much attention from organic and medicinal chemists. The main objective of writing this review is to draw attention to this apparent neglect. We predict that this fascinating area of the Baylis-Hillman reaction will receive considerable attention from synthetic chemists in the coming years and useful and interesting themes will be developed so as to demonstrate its power in synthetic, mechanistic and medicinal chemistry.

\section{Abbreviations}

$\begin{array}{ll}\text { Ac } & \text { acetyl } \\ \mathrm{BA} & \text { Brønsted acid } \\ \mathrm{Bn} & \text { benzyl } \\ \mathrm{Boc} & t \text {-butoxycarbonyl } \\ \mathrm{Bu} & \text { butyl } \\ \mathrm{Cbz} & \text { benzyloxycarbonyl }\end{array}$




$\begin{array}{lc}\text { CoA } & \text { Coenzyme A } \\ \text { Cp } & \text { cyclopentadienyl } \\ \text { DABCO } & \text { 1,4-diazabicyclo(2.2.2)octane } \\ \text { DBU } & \text { 1,8-diazabicyclo(5.4.0)undec-7-ene } \\ \text { DCM } & \text { dichloromethane } \\ \text { DIBAL-H } & \text { diisobutylaluminium hydride } \\ \text { DMAP } & \text { 4-(dimethylamino)pyridine } \\ \text { DME } & \text { 1,2-dimethoxyethane } \\ \text { DMF } & \text { N,N-dimethylformamide } \\ \text { DMP } & \text { Dess-Martin periodinane } \\ \text { Et } & \text { ethyl } \\ \text { EWG } & \text { electron withdrawing group } \\ \text { GLC } & \text { gas liquid chromatography } \\ \text { HMPA } & \text { hexamethyl phosphoramide } \\ \text { Me } & \text { methyl } \\ \text { Mes } & \text { mesityl } \\ \text { Nuc } & \text { nucleophilic center in S. spinosa (coenzyme) } \\ \text { PMB } & p \text {-methoxybenzyl } \\ \text { PPTS } & \text { pyridinium } p \text {-toluenesulfonate } \\ \text { Pr } & \text { propyl } \\ \text { SpnL } & \text { S. spinosa (coenzyme) } \\ \text { TBDPS } & \text { tert-butyldiphenylsilyl } \\ \text { TBS } & \text { tert-butyldimethylsilyl } \\ \text { THF } & \text { tetrahydrofuran } \\ \text { TIPS } & \text { triisopropylsilyl } \\ \text { Tr } & \text { trityl } \\ \text { Trs } & 2,4,6 \text {-triisopropylbenzenesulfonyl } \\ \text { Ts } & \text { tosyl } \\ & \end{array}$

\section{Acknowledgements}

We thank DST, CSIR, and UGC (New Delhi) for generous funding at various times to our long term major research program on the Baylis-Hillman reaction. We also thank UGC (New Delhi) for recognizing the School of Chemistry as a "Center for Advanced Studies in Chemistry" and for providing some instrumental facilities. GCR thanks CSIR and DST (New Delhi) for his research fellowship. 


\section{References}

1. Nicolaou, K. C.; Montagnon, T. Molecules that Changed the World, Wiley: Weinheim, 2008.

2. Corey, E. J.; Czakó, B.; Kürti, L. Molecules and Medicine, Wiley: New Jersey, 2007.

3. Surburg, H., Panten, J. Common Fragrance and Flavor Materials: Preparation, Properties and Uses, 5th Edn.; Wiley-VCH Verlag GmbH \& Co. KGaA, Weinheim, 2006.

4. Harris, F. W. J. Chem. Educ. 1981, 58, 837. http://dx.doi.org/10.1021/ed058p837

5. Smith, M. B. March's Advanced Organic Chemistry: Reactions, Mechanisms and Structure, 7th Edn.; Wiley: New Jersey, 2013.

6. Clayden, J.; Greeves, N.; Warren, S. Organic Chemistry, 2nd Edn.; Oxford, 2012.

7. Kürti, L.; Czakó, B. Strategic Applications of Named Reactions in Organic Synthesis, Elsevier, Burlington, 2005.

8. Carey, F. A.; Sundberg, R. J. Advanced Organic Chemistry: Parts A \& B, 5th Edn.; Springer: New York, 2007.

9. Larock, R. C. Comprehensive Organic Transformations: A Guide to Functional Group Preparations, 2nd Edn.; John Wiley \& Sons, Inc.: New York, 1999.

10. Baylis, A. B.; Hillman, M. E. D. German patent 2155113, 1972, Chem. Abstr. 1972, 77 , 34174q.

11. Hillman, M. E. D.; Baylis, A. B. U. S. Patent 3, 743, 669, 1973.

12. Morita, K.; Suzuki, Z.; Hirose, H. Bull. Chem. Soc. Jpn., 1968, 41, 2815. http://dx.doi.org/10.1246/bcsj.41.2815

13. Morita, K.; Kobayashi, T. Bull. Chem. Soc. Jpn., 1969, 42, 2732. http://dx.doi.org/10.1246/bcsj.42.2732

14. Wei, Y.; Shi, M. Chem. Rev. 2013, 113, 6659. http://dx.doi.org/10.1021/cr300192h

15. Basavaiah, D.; Reddy, B. S.; Badsara, S. S. Chem. Rev. 2010, 110, 5447. http://dx.doi.org/10.1021/cr900291g

16. Declerck, V.; Martinez, J.; Lamaty, F. Chem. Rev., 2009, 109, 1. http://dx.doi.org/10.1021/cr068057c

17. Singh, V.; Batra, S. Tetrahedron 2008, 64, 4511. http://dx.doi.org/10.1016/j.tet.2008.02.087

18. Basavaiah, D.; Rao, A. J.; Satyanarayana, T. Chem. Rev. 2003, 103, 811. http://dx.doi.org/10.1021/cr010043d

19. Ciganek, E. Organic Reactions; Paquette, L. A., Ed; New York: Wiley, 1997, vol. 51, p 201. http://dx.doi.org/10.1002/0471264180.or051.02

20. Basavaiah, D.; Rao, P. D.; Hyma, R. S. Tetrahedron 1996, 52, 8001. http://dx.doi.org/10.1016/0040-4020(96)00154-8

21. Drewes, S. E.; Roos, G. H. P. Tetrahedron 1988, 44, 4653. http://dx.doi.org/10.1016/S0040-4020(01)86168-8 
22. Bhowmik, S.; Batra, S. Curr. Org. Chem. 2014, 18, 3078.

http://dx.doi.org/10.2174/1385272819666141125003114

23. Basavaiah, D.; Sahu, B. C. Chimia 2013, 67, 8.

http://dx.doi.org/10.2533/chimia.2013.8

24. Basavaiah, D.; Veeraraghavaiah, G. Chem. Soc. Rev. 2012, 41, 68. http://dx.doi.org/10.1039/C1CS15174F

25. Liu, T.-Y.; Xie, M.; Chen, Y.-C. Chem. Soc. Rev. 2012, 41, 4101. http://dx.doi.org/10.1039/c2cs35017c

26. Kirandeep, K.; Namboothiri, I. N. N. Chimia 2012, 66, 913. http://dx.doi.org/10.2533/chimia.2012.913

27. Shi, Y.-L.; Shi, M. Org. Biomol Chem. 2007, 1499. http://dx.doi.org/10.1039/b618984a

28. Shi, Y.-L.; Shi, M. Eur. J. Org. Chem. 2007, 2905. http://dx.doi.org/10.1002/ejoc.200700030

29. Basavaiah, D.; Rao, K. V.; Reddy, R. J. Chem. Soc. Rev. 2007, 36, 1581. http://dx.doi.org/10.1039/b613741p

30. Masson, G.; Housseman, C.; Zhu, J. Angew. Chem. Int. Ed. 2007, 46, 4614. http://dx.doi.org/10.1002/anie.200604366

31. Rauhut, M. M.; Currier, H. American Cyanamide Co. U. S. Patent, 1963, 3074999. Chem. Abstr. 1963, 58, $11224 a$

32. Methot, J. L.; Roush, W. R. Adv. Synth. Catal. 2004, 346, 1035. http://dx.doi.org/10.1002/adsc.200404087

33. Aroyan, C. E.; Dermenci, A.; Miller , S. J. Tetrahedron 2009, 65, 4069 http://dx.doi.org/10.1016/j.tet.2009.02.066

34. Xie, P.; Huang, Y. Eur. J. Org. Chem. 2013, 6213. http://dx.doi.org/10.1002/ejoc.201300469

35. Roth, F.; Gygax, P.; Frater, G. Tetrahedron Lett. 1992, 33, 1045. http://dx.doi.org/10.1016/S0040-4039(00)91855-0

36. Drewes, S. E.; Njamela, O. L.; Emslie, N. D.; Ramesar, N.; Field, J. S. Synth. Commun. 1993, 23, 2807.

http://dx.doi.org/10.1080/00397919308012600

37. Ghandi, M.; Bozcheloei, A. H.; Nazari, S. H.; Sadeghzadeh, M. J. Org. Chem. 2011, 76, 9975.

http://dx.doi.org/10.1021/jo201506d

38. Ghandi, M.; Feizi, S.; Ziaie, F.; Notash, B. Tetrahedron 2014, 70, 2563. http://dx.doi.org/10.1016/j.tet.2014.02.038

39. Basavaiah, D.; Reddy, G. C.; Bharadwaj, K. C. Eur. J. Org. Chem. 2014, 1157. http://dx.doi.org/10.1002/ejoc.201301526

40. Tong, K.; Tu, J.; Qi, X.; Wang, M.; Wang, Y.; Fu, H.; Pittman, C. U.; Zhou, A. Tetrahedron 2013, 69, 2369. 
http://dx.doi.org/10.1016/j.tet.2012.12.083

41. Basavaiah, D.; Reddy, G. C.; Bharadwaj, K. C. Tetrahedron 2014, 70, 7991. http://dx.doi.org/10.1016/j.tet.2014.08.045

42. Trifonov, V. V.; Goncharov, V. I.; Aksenov, A. V. Chem. Heterocycl. Compd. 2006, 42, 955. http://dx.doi.org/10.1007/s10593-006-0186-Z

43. Pigge, F. C.; Dhanya, R.; Hoefgen, E. R. Angew. Chem. Int. Ed. 2007, 46, 2887. http://dx.doi.org/10.1002/anie.200605045

44. Pigge, F. C.; Dhanya, R.; Swenson, D. C. Organometallics 2009, 28, 3869. http://dx.doi.org/10.1021/om900178w

45. Krishna, P. R.; Kannan, V.; Sharma, G. V. M. J. Org. Chem. 2004, 69, 6467. http://dx.doi.org/10.1021/jo049511k

46. Zhou, A.; Hanson, P. R. Org. Lett. 2008, 10, 2951. http://dx.doi.org/10.1021/o18009072

47. Zhou, A.; Rayabarapu, D.; Hanson, P. R. Org. Lett. 2009, 11, 531. http://dx.doi.org/10.1021/o1802467f

48. Reddy, L. R.; Saravanan, P.; Corey, E. J. J. Am. Chem. Soc. 2004, 126, 6230. http://dx.doi.org/10.1021/ja048613p

49. Reddy, L. R.; Fournier, J-F.; Reddy, B. V. S.; Corey, E. J. Org. Lett. 2005, 7, 2699. http://dx.doi.org/10.1021/o10508734

50. Myers, E. L.; de Vries, J. G.; Aggarwal, V. K. Angew. Chem. Int. Ed. 2007, 46, 1893. http://dx.doi.org/10.1002/anie.200604715

51. Roe, S. J.; Stockman, R. A. Chem. Commun. 2008, 3432. http://dx.doi.org/10.1039/b804304c

52. Kurasaki, H.; Okamoto, I.; Morita, N.; Tamura, O. Org. Lett. 2009, 11, 1179. http://dx.doi.org/10.1021/o1900032h

53. Kurasaki, H.; Okamoto, I.; Morita, N.; Tamura, O. Chem. Eur. J. 2009, 15, 12754. http://dx.doi.org/10.1002/chem.200901843

54. Webber, P.; Krische, M. J. J. Org. Chem. 2008, 73, 9379. http://dx.doi.org/10.1021/jo802165k

55. Raheem, I. T.; Goodman, S. N.; Jacobsen, E. N. J. Am. Chem. Soc. 2004, 126, 706. http://dx.doi.org/10.1021/ja039550y

56. Yagi, K.; Turitani, T.; Shinokubo, H.; Oshima, K. Org. Lett. 2002, 4, 3111. http://dx.doi.org/10.1021/o1026413h

57. Wang, L-C.; Luis, A. L.; Agapiou, K.; Jang, H-Y.; Krische, M. J. J. Am. Chem. Soc. 2002, 124, 2402. http://dx.doi.org/10.1021/ja0121686

58. Frank, S. A.; Mergott, D. J.; Roush, W. R. J. Am. Chem. Soc. 2002, 124, 2404. http://dx.doi.org/10.1021/ja017123j

59. Luis, A. L.; Krische, M. J. Synthesis 2004, 2579. 
60. Wang, X-F.; Peng, L.; An, J.; Li, C.; Yang, Q-Q.; Lu, L-Q.; Gu, F-L.; Xiao, W-J. Chem. Eur. J. 2011, 17, 6484 . http://dx.doi.org/10.1002/chem.201100479

61. Takizawa, S.; Nguyen, T. M-N.; Grossmann, A.; Enders, D.; Sasai, H. Angew. Chem. Int. Ed. 2012, 51, 5423. http://dx.doi.org/10.1002/anie.201201542

62. Su, X.; Zhou, W.; Li, Y.; Zhang, J. Angew. Chem. Int. Ed. 2015, 54, 6874. http://dx.doi.org/10.1002/anie.201500907

63. Takizawa, S.; Nguyen, T. M-N.; Grossmann, A.; Suzuki, M.; Enders, D.; Sasai, H. Tetrahedron 2013, 69, 1202. http://dx.doi.org/10.1016/j.tet.2012.11.046

64. Scanes, R. J. H.; Grossmann, O.; Grossmann, A.; Spring, D. R. Org. Lett. 2015, 17, 2462. http://dx.doi.org/10.1021/acs.orglett.5b00971

65. Jin, Z.; Yang, R.; Du, Y.; Tiwari, B.; Ganguly, R.; Chi, Y. R. Org. Lett. 2012, 14, 3226. http://dx.doi.org/10.1021/ol3013588

66. Mergott, D. J.; Frank, S. A.; Roush, W. R. Proc. Natl. Acad. Sci. U.S.A. 2004, 101, 11955. http://dx.doi.org/10.1073/pnas.0401247101

67. Winbush, S. A. M.; Mergott, D. J.; Roush, W. R. J. Org. Chem. 2008, 73, 1818. http://dx.doi.org/10.1021/jo7024515

68. Kim, H. J.; Ruszczycky, M. W.; Choi, S-h.; Liu, Y-n.; Liu, H-w. Nature 2011, 473, 109. http://dx.doi.org/10.1038/nature09981

69. Dermenci, A.; Selig, P. S.; Domaoal, R. A.; Spasov, K. A.; Anderson, K. S.; Miller, S. J. Chem. Sci. 2011, 2, 1568.

http://dx.doi.org/10.1039/c1sc00221j

\section{Authors' Biographies}

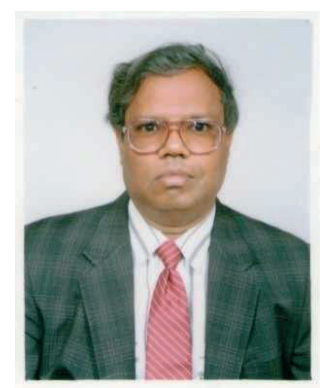

\section{Professor D. Basavaiah}

School of Chemistry, University of Hyderabad, Hyderabad-500 046

D. Basavaiah was born in Valiveru (a village near Tenali), India. He had his School education in ZPH School, Edlapalli (near Tenali). He obtained B.Sc degree from Andhra University 
(India) in 1970 and M.Sc. (Organic Chemistry) degree from the Banaras Hindu University (BHU) (India) in 1972. He received BHU Gold Medal for obtaining First Rank in M.Sc examinations. Afterwards he worked in the research group of Professor Gurbakhsh Singh and obtained Ph. D. degree from BHU in the year 1979. Then he worked in the research group of Professor Herbert C. Brown at Purdue University (August 1980-November 1983), USA as a post-doctoral fellow. He returned to India in the month of November 1983 and worked for a short time as a Scientist (January 1984-June 1984) at the National Chemical Laboratory, Pune. In June 1984 he joined the School of Chemistry, University of Hyderabad, Hyderabad where he is currently a Professor. He has been working on various aspects of the Baylis-Hillman reaction during the past 31 years with the main objective of developing this reaction into a powerful and useful $\mathrm{C}-\mathrm{C}$ bond forming reaction in synthetic chemistry and in fact, made fundamental, original, and pioneering contributions to this reaction. He has been teaching organic chemistry to M.Sc (also integrated M.Sc.) students at the University of Hyerabad during the past 31 years.



Guddeti Chandrashekar Reddy was born in 1985 in Amadabakula, (a village near Mahabubnagar) Telangana, India. He obtained B. Sc. (2005) and M. Sc. (2008) from Osmania University, Hyderabad. Presently he is working for Ph. D. in the School of Chemistry, University of Hyderabad under the supervision of Professor D. Basavaiah. His work deals with the development of intramolecular Baylis-Hillman reaction. 